\title{
Do spatial interactions fuel the climate-conflict vicious cycle? The case of the African continent
}

\author{
Federica Cappelli ${ }^{1}$ - Caterina Conigliani ${ }^{1}$ - Valeria Costantini ${ }^{1,2}$ (D) \\ Keti Lelo ${ }^{1} \cdot$ Anil Markandya $^{3} \cdot$ Elena Paglialunga $^{4} \cdot$ Giorgia Sforna $^{5}$
}

Received: 8 January 2020 / Accepted: 28 October 2020 / Published online: 17 November 2020

(C) The Author(s) 2020

\begin{abstract}
We propose an analysis of the multiple linkages between violent conflicts, weatherrelated variables and socio-economic conditions based on an original geo-referenced database covering the entire African continent with a grid resolution of $1^{\circ} \times 1^{\circ}$ for the period 1990-2016. We implement a dynamic spatial panel Durbin model that allows us: (1) confirming well-known mechanisms in violent conflicts analysis; (2) assessing the relevance of persistency of violence over time; (3) adding new insights related to the role of spatial relations associated to contagion. In particular, the spatial specification allows us quantifying the contagious effect across space, that persists in a radius of more than $300 \mathrm{~km}$. Weather-related variables seem to play a prominent role in shaping contagion with different strength depending on the temporal horizon adopted. The main implications we derive are twofold: (1) adaptation policies designed for reducing vulnerability of local communities to climate change must be integrated with direct actions for peacekeeping in order to break the persistency of violence over time that is responsible for failures of the adaptation actions themselves; (2) synergies from simultaneous actions developed for different local communities must drive geographical coordination of integrated policies in order to capture the positive elements of cooperation associated to geographical spillovers while breaking violence contagion across neighbours.
\end{abstract}

Keywords Climate change · Violent conflicts · Africa - Geographical spillovers · Dynamic panel spatial Durbin model

JEL Classification D74 · O13 · O55 - Q54

Electronic supplementary material The online version of this article (https://doi.org/10.1007/s43071020-00007-8) contains supplementary material, which is available to authorized users.

Extended author information available on the last page of the article 


\section{Introduction}

Armed conflicts wreak disorder on economies and have devastating effects on development. According to Gates et al. (2012), about a quarter of the population of the developing world lives in conflict and post-conflict countries. During last decades, African countries have especially experienced many conflicts and civil wars. In addition, the continent also suffers from the challenges of poverty, limited education and health systems, food insecurity and, last but not least, the negative impacts of severe changes in climate conditions. Although climate change is a global threat, developing countries (DCs) and especially the African ones suffer the most due to their greater vulnerability to climatic factors (Moore and Diaz 2015).

For these reasons, the African continent has been continuously put under the lens of empirical investigation of the climate-conflict nexus. Changes in temperature and rainfall patterns are estimated to affect a large share of population, influencing their lives and creating further incentives for violent attacks and armed conflicts in the near future (Dell et al. 2014; Miguel et al. 2004).

Although the recent comprehensive review by Koubi (2019) covers numerous academic studies exploring the climate-conflict link, there is still debate on whether a change in weather conditions systematically increases conflict risk. To this purpose, Mach et al. (2019), through an expert-based analysis, find that low socioeconomic development and capabilities are judged to be drivers substantially more influential than changes in climate conditions, which in turn are estimated to increase the risk of conflicts in the future on account of the uncertainty they present.

Nonetheless, Buhaug (2015) and Ide et al. (2014) note that socio-economic factors, including the demographic pressure, the quality of institutions and political exclusion of ethnic groups, are not only direct drivers of conflicts but substantially influence also the impact of weather conditions on conflicts. The economic structure of countries, their poor institutional capacity, unequal income distribution, the scarcity of financial resources to implement adaptation measures and the consequent low resilience to extreme events and disasters contribute to the complexity of mechanisms behind the vicious cycle of violence (Burke et al. 2015; Hsiang et al. 2011). This complexity is well explained by the comprehensive concept of social vulnerability to climate change (Otto et al. 2017).

Moreover, the uncertainty on the direction and relative magnitude of linkages between changes in weather conditions and conflicts is found to strongly depend on the plethora of different approaches in empirical design related to data collection with heterogeneous temporal, geographic, and social scales and the quantitative methods implemented (Ide 2017; Salehyan 2014), leaving space for further development in research design.

In this paper we propose a quantitative approach that aims contributing to the debate in two aspects.

First, we apply a dynamic spatial panel econometric analysis based on a Durbin model, which allows simultaneous consideration of driving factors of the geographic unit under scrutiny and those of the surrounding areas. As emphasised in Ide (2017), statistical analysis using sub-national data rarely account for the fact 
that climate-related conflicts do not necessarily take place where the effects of climate change are most severe. By using an original panel dataset for the entire African continent at a sub-national scale for the time span 1990-2016, the dynamic Durbin model is applied to a cell-based geographic detail corresponding to a grid of 3402 units of observation of $1^{\circ} \times 1^{\circ}$ (corresponding to an area around $110 \times 110 \mathrm{~km})$. By including a wide range of cell-based and country-based socio-economic and weather variables, we can control for the socio-economic vulnerability of local areas to different ranges of influence (Auffhammer et al. 2013; Busby et al. 2014; Devlin and Hendrix 2014; Maystadt et al. 2015), exploiting the powerful instrument of spatial econometric interaction modelling (Arbia and Patuelli 2016; LeSage and Pace 2009). Given the nature of the vicious cycle of violence that is persistent over time and space, the adoption of a dynamic Durbin model allows jointly taking into account the effect of contagion at a global scale occurring all over the continent.

Second, instead of confining the analysis to the occurrence or not of violence, we account for the total number of events defined as an armed conflict, where an event is counted if the conflict causes at least one death. The empirical estimation must be interpreted as the effects of the explanatory variables not only on the probability of a cell to be violent or not (as in the case of binary information) but also on the relative strength of violence if several episodes occur in the same place over the same year. This allows partly solving the shortcoming related to differences in conflict coding systems as emphasised by Selby (2014). Given that conflict datasets vary in their typologies and classifications, as well as in thresholds used to mark conflict onset, by simply changing the statistical source empirical results might change.

The remainder of the article is organised as follows. In Sect. 2 we review main analytical methods developed by the literature in order to select variables to be included in the database and to choose the appropriate econometric technique. In Sect. 3 we describe the econometric methodology and the dataset. In Sect. 4 we comment on main results, while in Sect. 5 we discuss concluding remarks and offer future research lines.

\section{Research methods and empirical approaches: an open debate}

The two most common methods used in the field of weather conditions and armed conflicts linkages are: large- $\mathrm{N}$ statistical analysis and qualitative case study. As emphasised by Salehyan (2014), the choice of the research method, together with the specific scale of investigation, might explain a large portion of divergence in empirical findings on this topic. In this paper we focus on a large-N statistical approach because we take the view that a dynamic spatial econometric model is most able to offer insights into the potential role played by geographical spillovers in explaining how weather conditions might impact the vicious cycle of violence.

The most recent developments for large- $\mathrm{N}$ analysis allow for the detection of potential linkages at the sub-national level, using artificial grid cells, administrative areas, or ethnic groups as the unit of analysis (Ide 2017). The strongest motivation for choosing such method in regression analysis is that it is characterized by high 
external validity because its inferences are supported by a large number of cases. The wider the geographical coverage of the database, the higher the potential for generalisation of results.

In particular, by adopting a grid approach that covers an entire continent, it is possible to account for all elements explaining why certain places are more likely to experience a conflict than others. By including also areas not affected by conflicts, if the estimated coefficient for an explanatory variable is statistically significant, we can conclude that it represents a driving factor of conflicts without suffering from sample bias. It is worth mentioning that the sample bias problem is completely solved only if the whole world is included, while results obtained for a single continent can be considered as generally valid only for that area.

While a large-N scale analysis based on grid approach has the cited advantages, it also has several shortcomings. According to Koubi (2019), the lack of conclusive empirical evidence linking climatic changes with conflicts is largely due to the inability of the existing approaches to adequately model the complexity of the nexus. As emphasised by Ide (2017), the way forward in research design is to combine different research methods, as for instance the integration of statistical techniques with qualitative case studies, or the use of geographical information systems (GIS) for risk evaluation.

We also acknowledge that the selection of a single continent analysed with subnational data presents advantages and disadvantages. According to Ide and Scheffran (2014), this scale of analysis better captures micro-level phenomena (e.g. intrastate migration and resource distribution at the local level), which depend on geographical and landscape characteristics, rather than on administrative boundaries, as in country-based analyses. To this purpose, the contribution by Harari and La Ferrara (2018) shows that a sub-national analysis applied to Africa as a continent helps in discovering fine-grained events as the role played by rainfall changes during the crop growing season in reinforcing the possibility of conflict, considering that the same weather condition can affect places without any conflict. Nonetheless, Adams et al. (2018) show that the over-representation of Africa or selected African sub-regions could be driven by the fact that these regions experience many violent events and at the same time they are largely affected by variations in the precipitation patterns and temperature change (Ember et al. 2012; Hsiang et al. 2011; Maystadt and Ecker 2014; Raleigh and Kniveton 2012). Accordingly, the implementation of a dynamic spatial econometric analysis applied to Africa as a continent at the grid level should be taken as a first step toward a full global coverage of conflicts and weather conditions for completely generalised results. 


\section{Methods and data}

\subsection{Methods}

We adopt a dynamic panel spatial approach in order to account for the geographical scale and the temporal dimension of the linkages between changes in climaterelated variables and armed conflicts.

Notice that from the point of view of the spatial configuration, different types of interaction effects can explain why an observation at a specific location may depend on observations at other locations (Elhorst 2014). The first are endogenous interaction effects, where the response variable $Y$ of a particular unit depends on the response variable $Y$ of neighbouring units. The second are exogenous interaction effects, where the response variable of a particular unit depends on explanatory variables $X$ of neighbouring units. The third are interaction effects among the error terms, that represent, for instance, a situation where the determinants of the response variable omitted from the model are spatially correlated. All these interaction effects can be introduced in a spatial econometric model by means of a non-negative (and usually symmetric) weights matrix that describes the spatial configuration of the units in the sample.

From the point of view of the panel structure of our data, both spatial and temporal heterogeneity can be accounted for. In fact, units are likely to differ in their background variables, such as the distance from the sea or from the border, or the degree of urbanization, which are usually space-specific and time-invariant. Similarly, units are likely to differ over time, due, for instance, to time points marked by an economic recession, by a boom, or by a change in legislation. Failing to account for these spatial and temporal effects can lead to biased estimation results due to serial correlation of the residual term. In particular, spatial and temporal heterogeneity could be considered within a fixed or a random effects approach. However, random effects models require the assumption of zero correlation between the random effects and the explanatory variables; moreover, they also require that the number of units should potentially be unbounded and that the units of observation are representative of a larger population. On the contrary, in several spatial econometric analyses the data are generally relative to adjacent spatial units located in an unbroken area (such as all regions in a country), so that they cover the whole population and each unit represents itself (Elhorst 2014). For this reason, in what follows we will concentrate on fixed effects models.

Finally, given the persistence over time of the conflictual propensity and intensity of cells and the potential mutual correlation between conflicts and some explanatory variables representing social vulnerability, our model also allows for temporal lags of order $p$. Its general form can be written as:

$$
\begin{gathered}
Y_{i t}=\alpha Y_{i t-p}+\rho \boldsymbol{W} Y_{j t}+\beta X_{i t-p}+\vartheta \boldsymbol{D} X_{j t-p}+\gamma_{i}+\delta_{t}+u_{i t} \\
u_{i t}=\lambda \boldsymbol{M} u_{j t}+\varepsilon_{i t}
\end{gathered}
$$


where $\alpha$ is the coefficient associated with persistence over time, $\rho$ is the spatial autoregressive coefficient representing the endogenous interaction effect (introduced by means of the spatial weight $N x N$ matrix $\boldsymbol{W}), \beta$ is the vector of parameters associated with the explanatory variables of the statistical unit, $\vartheta$ is the vector of parameters associated with the spatial exogenous interaction effects (introduced by means of the spatial weight $N x N$ matrix $\boldsymbol{D}), \gamma_{i}$ are cell-specific fixed effects, $\delta_{t}$ are year-specific fixed effects, $\lambda$ is the spatial autocorrelation coefficient representing the interaction effects among the disturbance term of the different units (introduced by means of the spatial weight matrix $\boldsymbol{M}$ ), and $\varepsilon_{i t}$ is an $N \times 1$ vector of independent and identically distributed (i.i.d.) homoscedastic normal disturbance terms. It is worth mentioning that the model allows the weighting matrices associated with the spatial autoregressive term, the spatial exogenous effects and the spatial autocorrelation coefficient ( $\boldsymbol{W}, \boldsymbol{D}, \boldsymbol{M}$ respectively) to be different.

Notice that, as pointed out for instance in Elhorst (2014), the full model specified in (1) and (2) is usually over-parametrised, so that the significance levels of the explanatory variables tend to decrease and in empirical studies it does not appear to outperform simpler models. In particular, Le Sage and Pace (2009) point out that, in order to impose restrictions in the full model, it is important to take into account the fact that the cost of ignoring spatial dependence in the response and/or in the predictors is relatively high, since if a relevant explanatory variable is omitted from a regression equation, the estimator of the coefficients for the remaining variables can be biased and inconsistent. On the other hand, ignoring spatial dependence in the disturbances, if present, will only cause a loss of efficiency.

For this reason, among the possible models with two types of interaction effects, they recommend the use of the Spatial Durbin Model (SDM), with $\rho, \vartheta \neq 0$ and $\lambda=$ 0 (Anselin 1988; Anselin et al. 1996; LeSage and Pace 2009). Notice that the SDM is particularly interesting with respect to both the SAC model (with $\rho, \lambda \neq 0$ and $\vartheta=0$ ), as it imposes no restrictions on the magnitude of both the direct and indirect effects (Elhorst 2014), and the SDEM model (with $\lambda, \vartheta \neq 0$ and $\rho=0$ ), as it allows computing global effects associated to contagion via the endogenous interactions. It is also important to note that in our specific case the choice of a model including spatial dependence in the response, and therefore of the SDM (given the aforementioned limitations of the SAC), is also supported by the vast literature on conflicts pointing out that spatial units surrounded by units with conflicts are more likely to develop conflicts themselves (Jehn et al. 2013). Because of all the above considerations, the SDM has been the starting point of our analysis.

The final model selection, comparing the SDM with the simpler models that are nested in it, i.e. the SAR model (with $\rho \neq 0$ and $\vartheta, \lambda=0$ ) and the SLX model (with $\vartheta \neq 0$ and $\rho, \lambda=0$ ), has been based on the Akaike information criterion (AIC) and the Bayesian information criterion (BIC), as well as on Likelihood Ratio tests. As a result, the SDM in our case appear to be the most appropriate model to perform the analysis accounting for temporal dynamics and spatial spillovers. AIC and BIC have also been employed for selecting temporal lags of order $p$, with a final SDM with lag 1 for both the persistence term associated to parameter $\alpha$ and the indirect effects associated with parameter $\vartheta$. 
A complete dynamic setting for a SDM is formed by introducing a time lag for the dependent variable $\left(\alpha Y_{i t-p}\right)$ as in Eq. (1) and, eventually, a time lag for the spatially lagged dependent variable $\left(\eta \boldsymbol{W} Y_{j t-p}\right)$. In this modelling exercise we have adopted the restriction $\eta=0$ since the estimated coefficient for $\eta$ is always not statistically significant.

With respect to the choice of the spatial resolution, given that the selection of the geographical scale is not a priori determined on a theoretical basis but it is mainly driven by empirical findings as well as by data availability, we adopt units of observation of $1^{\circ} \times 1^{\circ}$ (approximately $110 \times 110 \mathrm{~km}^{2}$ ) relying on the most recent analysis of the climate-conflict nexus in Africa with a cell-based approach, represented by the contribution of Harari and La Ferrara (2018) where robustness checks on alternative resolution scales (both lower and higher) confirm the $1^{\circ} \times 1^{\circ}$ as the most appropriate. ${ }^{1}$

Another aspect to be carefully considered is the spatial spillover effect. First, recalling that if an explanatory variable $X_{k}$ changes in a particular unit, not only it will change the response variable in that unit (which is the direct effect), but also the response variable in other units are changed (which is the indirect or spillover effect). Because of these feedback effects, that arise due to the impacts passing through neighbouring units and back to the units themselves, conclusions about spatial spillovers in general cannot be drawn by simply looking at the parameters of the model but require the computation of a partial derivative (LeSage and Pace 2009).

In particular, according to the notation in Elhorst (2012), in a dynamic SDM the diagonal elements of the partial derivative of $E(Y)$ with respect to $X_{k}$ for the full model without constraints to spatial coefficients are equal to:

$$
\left[\frac{\partial Y}{\partial x_{1 k}} \cdots \frac{\partial Y}{\partial x_{N k}}\right]=\left[(I-\rho \boldsymbol{W})^{-1}\left(\beta_{k} I_{N}+\vartheta_{k} \boldsymbol{D}\right)\right]^{\bar{d}}
$$

and they represent the short-term direct effects of $X_{k}$. The off-diagonal elements of the same matrix represent the short-term indirect effects as follows:

$$
\left[\frac{\partial Y}{\partial x_{1 k}} \cdots \frac{\partial Y}{\partial x_{N k}}\right]=\left[(I-\rho \boldsymbol{W})^{-1}\left(\beta_{k} I_{N}+\vartheta_{k} \boldsymbol{D}\right)\right]^{\overline{r s u m}}
$$

Such elements represent proportional marginal effects and can thus be considered as elasticities.

More specifically, direct effects describe the impact that a percentage change in an independent variable in cell $i$ has on conflicts in the same cell (with respect to other cells). Indirect effects are interpreted as the impact that a percentage change in an independent variable in the other cells has on conflicts in cell $i$. Accordingly, empirical results reported in the main text and related comments on linkages strength and direction refer to direct and indirect effects calculated as in Eqs. (3)-

\footnotetext{
1 Different scales for the grid resolution are also constrained by data availability for the socio-economic vulnerability dimension, especially reflecting the grid resolution of $1^{\circ} \times 1^{\circ}$ of gross cell product values provided by G-Econ dataset v4.0, which is the original database from where gross cell product is calculated for different geographical scales.
} 
(4) only for models that are stable and significant, while coefficient estimates $\left(\beta_{k}, \vartheta_{k}\right)$ are reported in "Appendix 2" for all tested models. ${ }^{2}$

Finally, in a dynamic SDM (where the lagged dependent variable is introduced among the covariates but the restriction $\eta=0$ is applied) there is a further distinction to make, between short- and long-term effects. Specifically, the longterm direct effects are given by the diagonal elements of the matrix of partial derivatives of $Y$ with respect to the $k$-th explanatory variable in unit 1 up to unit $N$ :

$$
\left[\frac{\partial Y}{\partial x_{1 k}} \cdots \frac{\partial Y}{\partial x_{N k}}\right]=\left\{[(1-\alpha) I-\rho \boldsymbol{W}]^{-1}\left(\beta_{k} I_{N}+\vartheta_{k} \boldsymbol{D}\right)\right\}^{\bar{d}}
$$

while the long-term indirect effects are given by:

$$
\left[\frac{\partial Y}{\partial x_{1 k}} \cdots \frac{\partial Y}{\partial x_{N k}}\right]=\left\{[(1-\alpha) I-\rho \boldsymbol{W}]^{-1}\left(\beta_{k} I_{N}+\vartheta_{k} \boldsymbol{D}\right)\right\}^{\overline{r s u m}}
$$

where $\tau$ is the time lag of the variable $Y$.

The quantification of the contagion effect associated to conflicts occurring in surrounding areas, here represented by the spatial lag, and of the direct and indirect marginal effects, which hereafter we generally refer to as spillovers, is strongly influenced by the choice of the weighting distance system. Given that the whole African continent is here artificially gridded with a $1^{\circ} \times 1^{\circ}$ resolution, computing distance matrices on the basis of a pure contiguity criterion might lead to biased results if we do not account for what is happening outside the first ring of cells, corresponding to an inverse distance between centroids by around $180 \mathrm{~km}$. Accordingly, we apply the Mercator's projection map accounting for the spheroidal form of the Earth and compute inverse great circle distances via the so called Harversine formula calculated between the centroids of cells. The inverse distance has also been combined with the 'queen contiguity approach' when choosing the cut-off, in order to consider all cells being included or even also tangent for a single point with respect to the buffer computed with the radius equal to the cut-off distance expressed in $\mathrm{km}^{3}$

Notice that although it is common practice to normalize distance weight matrices such that the elements of each row sum to unity, so that the weighting operation can be interpreted as an averaging of neighbouring values, following Harari and La Ferrara (2018) we do not make use of row normalization. In fact, row normalization alters the internal weighting structure of $\boldsymbol{W}$, in the sense that it has the effect of understating the weights of a unit with many neighbours with respect to those of a unit that is located near the boundary: pairs with the same distance can have

\footnotetext{
${ }^{2}$ Direct, indirect and total effects as well as their standard errors are computed by using Monte Carlo simulations. Standard errors for marginal effects reported in Tables in the main text are available upon request from the authors.

${ }^{3}$ We are aware of drawbacks of the Harversine formula that provides valid measures for short distances but underestimated values for long distances especially if calculated in places far from the Equator line where the Rhumb lines approach is more appropriate. Nonetheless, given that our maximum cut-off distance is around $568 \mathrm{~km}$ of radius, difference between the two approaches is negligible (Weintrit and Kopacz 2011).
} 
different weights depending on the number of nearby observations (LeSage and Pace 2014).

In order to choose the cut-off for the three weight matrices (respectively $\boldsymbol{W}, \boldsymbol{D}, \boldsymbol{M})$ we used two criteria. First, we compute global Moran's I in order to detect for each variable the maximum distance where spatial correlation is significantly different from zero. Second, we adopt different cut-off values for the same econometric model in order to choose the estimates that perform better in terms of the AIC and BIC values and the stability of the dynamic specification according to Lee and Yu (2010). Results described in Sect. 4 are thus based on optimal cut-offs of $250 \mathrm{~km}$ for the contagion effect and of $500 \mathrm{~km}$ for spillover effects. By relying on the combination of great circle distances with the queen contiguity criterion, the actual size of buffers projected on a bi-dimensional space corresponds to radius equal to around 311 and $568 \mathrm{~km}$, respectively. For the sake of simplicity in the rest of the text we will refer to them as 250 and $500 \mathrm{~km}$.

It is worth mentioning that the optimal cut-off for spillover effects is heterogeneous with respect to different dimensions. In particular, for those variables representing social vulnerability such as income and population, the cut-off obtained with the global Moran's I corresponds to the $500 \mathrm{~km}$ distance; instead, for climate-related variables as temperature and precipitation the spatial correlation is significantly different from zero with a cut-off of $1000 \mathrm{~km}$ (around $1111 \mathrm{~km}$ radius of the actual buffer). However, given that a common weight matrix $(\boldsymbol{D})$ should be adopted for all covariates in the STATA package, we consider the $500 \mathrm{~km}$ cut-off in order to account for spillover effects also for social vulnerability. ${ }^{4}$

\subsection{Data}

The empirical analysis is conducted on an original georeferenced database that combines conflict data with climate and socio-economic information resulting in a panel dataset for the entire African continent divided into 3402 georeferenced cells covering the period from 1990 to 2016 . $^{5}$ Statistical sources for armed conflicts are today widely used and continuously updated. To the best of our knowledge the two sources are mainly used for empirical analysis are ACLED (Armed Conflict Location \& Event Data Project) and UCDP-GED (Uppsala Conflict Data ProjectGeoreferenced Event Dataset). We build the dependent variable by taking raw data from the UCDP-GED database (Croicu and Sundberg 2017; Högblad 2019;

\footnotetext{
${ }^{4}$ Details related to the choice of cut-offs, global Moran's I values for main variables and representation of the radius computation for different buffers are provided in Appendix A. Values for global Moran's I for all variables as well as values for local Moran's I are available upon request from the authors.

5 The 48 countries included are: Algeria, Angola, Benin, Botswana, Burkina Faso, Burundi, Cameroon, Central African Republic, Chad, Congo, Cote d'Ivoire, Democratic Republic of Congo, Djibouti, Egypt, Equatorial Guinea, Eritrea, Ethiopia, Gabon, Gambia, Ghana, Guinea, Guinea Bissau, Kenya, Lesotho, Liberia, Libya, Madagascar, Malawi, Mali, Mauritania, Morocco, Mozambique, Namibia, Niger, Nigeria, Rwanda, Senegal, Sierra Leone, Somalia, South Africa, Sudan, Swaziland, Tanzania, Togo, Tunisia, Uganda, Zambia, Zimbabwe. Benin, Equatorial Guinea, Gabon, Gambia and Malawi have been included even if no conflicts have been registered for these countries in the UPPSALA-UCDP, while we excluded island countries (Cape Verde, Comoros, Mauritius, São Tomé and Príncipe, Seychelles). South Sudan has been classified as Sudan for combining country-based information.
} 
Sundberg and Melander 2013), that provides information on conflicting events with geographical coordinates at a very detailed level. We define our dependent variable (hereafter referred to as number of conflicts) as the sum of all conflicting events that occurred in a specific year whose geographical coordinates are included in the area covered by the cell itself. Conflicting events are defined as incidents where armed force is used by a government or by any organised actor against another organised actor, or against civilians, resulting in at least one direct death at a specific location and a specific date. Interstate armed conflicts fought between two or more states are excluded. This choice presents several positive aspects with respect to ACLED database, that is also often used for conflicts analysis. First, ACLED has a limited time span starting from 1997 while UCDP starts from 1989. Second, ACLED does not allow conflicts to be distinguished on the basis of the number of deaths. Third the quality of UCDP geocoding and precision information if the scale of the analysis is at the subnational level, is far superior to ACLED (Eck 2012) and allows counting with geographical precision the number of events occurred each year in each cell. This is particularly important given that the purpose of our analysis is to quantify to what extent short and medium-term change in weather conditions can be associated to the magnitude of violent events, and not only to an increased probability of experiencing at least one conflict. ${ }^{6}$

Given the grid approach we have adopted, the most complete source of statistical information covering different aspects such as climatic variables and socioeconomic conditions is the UCDP-PRIO (Peace Research Institute Oslo) grid database (Gleditsch et al. 2002). Despite its global geographical coverage, UCDPPRIO has severe shortcomings for our research purpose, due to lack of information for recent years for key variables, as for instance the cell-based income (2005 as the last available year) or precipitations (2013 as the last available year). Accordingly, we have started from raw information available from the UCDP-PRIO where possible, and we have updated variables up to 2016 and included in the dataset several additional statistical sources as follows.

The explanatory variables related to weather conditions represent both punctual conditions related to the geo-localisation of each cell and changes occurring in the short and medium-term elaborated from the African Flood and Drought Monitor developed by Princeton University in collaboration with ICIWaRM and UNESCOIHP (with an original resolution of $0.25^{\circ}$ degrees). ${ }^{7}$

Concerning temperature, we consider temperature measured at two meters above the surface and calculated from averaging monthly data. Data from 1990 to 2008 rely on the Princeton Global forcing methodology while from 2009 to 2016 they are taken from the Global Forecasting System Analysis. Original data expressed in the Kelvin scale have been converted in Celsius (centigrade) degrees. We compute temperature change rates w.r.t. the previous year in order to account for short-term variations, that can be interpreted as temporary anomalies or shocks. By also calculating the average yearly temperature change rates over the past 5 years we

\footnotetext{
6 The total number of events for the African continent in the time span 1990-2016 used for building the dependent variable corresponds to 34,605 observations.

7 http://stream.princeton.edu/AWCM/WEBPAGE/interface.php?locale=en.
} 
control for persistency of increasing (or decreasing) temperature over time as an indication of medium-term change in weather conditions.

With respect to precipitation, annual average precipitation values expressed as daily total surface precipitation in $\mathrm{mm} /$ day are computed by using monthly data from the Princeton Global forcing methodology for the period 1990-2008 and from Satellite Precipitation (3B42RT) for the period 2009-2016. Also in this case, we compute changes occurring with a 1-year lag in order to account for short-term variations (anomalies) and average precipitation changes over the past 5 years as a measure of medium-term changing conditions.

We also compute an annual average Standard Precipitation Index (SPI-12) that is a comparison in terms of standard deviation of the precipitation for 12 consecutive months with that recorded in the same 12 consecutive months in all previous years of available data and it can be interpreted as an index of meteorological drought where negative values represent dry conditions. ${ }^{8}$ With respect to the other meteorological composite indices, SPI is recommended since it is considered as computationally feasible and homogeneously available for all regions (WMO 2018). In addition, in this analysis we choose to include climatic conditions such as precipitation and temperature as distinguished variables. Accordingly, we have considered the SPI as it is based only on precipitation values, leaving temperature outside. As emphasised in recent contributions (Burke et al. 2015; Eckstein et al. 2017) temperature should be considered as a separate variable in such kind of analyses especially for the African continent, because rainfalls and temperature present quite divergent trends and deserve to be considered simultaneously but separately. Coherently with the other climatic variables, we also compute an average SPI-12 over the past 5 years that may be interpreted as a measure of drought persistency over a medium-term horizon.

In order to account for specific geographical features that may help in detecting differentiated vulnerability to climate change, we have also included some time invariant variables: (1) a dummy variable assuming value 1 if land cover is classified as cropland according to MODIS-based Global Land Cover Climatology dataset; (2) the water stress of each cell described in terms of drought severity and flood occurrence indices taken from the Aqueduct Water Risk Atlas.

With respect to the information related to rural coverage, we have computed a time variant cell-based variable by interacting the rural coverage at the cell level with the percentage of value added coming from the agricultural sector for each year at the country level taken from the World Development Indicator (WDI) database from the World Bank. By doing so, we are able to consider the relative relevance of land use while also accounting for how much the whole country depends on the primary sector. Given that this is the most affected sector in Africa from changes in climatic conditions, assigning an economic value to this geographical feature allows us to account for vulnerability also from a socio-economic point of view. Notice that

\footnotetext{
8 The SPI-12 is the Standard Precipitation Index indicating deviations from long-term normal rainfall during the 12 preceding months for each month (ranging from -3.719 to +3.719 ). If positive, it represents that the level of actual precipitation was higher than what expected or, in other word, it has been less dry.
} 
all these variables have been used for computing interaction effects in order to better shape differentiated vulnerability to changes in climatic conditions.

In particular, we interact short and medium-term changes in temperatures with drought-risk level, short and medium-term changes in precipitations with the time variant rural-related interacted variable, and with drought-risk and flood-risk levels. The same method is applied when interacting the SPI-12 and its average value over 5 years with rural, drought-risk and flood-risk features. The use of interaction terms between climatic variables and cell-specific features as drought or flood risk allows one to take account of the fact that the same absolute deviation in temperature or precipitations can have very different impacts if it occurs in relatively wet areas compared to drier ones. According to Linke et al. (2018), an increase in temperature in areas more vulnerable to drought is more likely to induce human relocation that in turn is often associated with an increase in violent events affecting people that decide to move.

Socio-economic vulnerability is represented by five dimensions, the value of gross cell product (GCP), the level of population, the variation of GCP per capita occurred in the previous year, the presence of mineral and fossil resources (cellbased) and the quality of institutions (country-based).

Original values of GCP and population level are taken by SEDAC-Socioeconomic Data and Applications Center database, available at the $1^{\circ} \times 1^{\circ}$ grid level for the period 1990-2005. Population data for the period 2006-2016 have been integrated with information coming from the History Database of the Global Environment (HYDE, version 3.2.1), checking for consistency among the two statistical sources. Data for GCP are based on the original information available from G-Econ dataset v4.0 that is used by SEDAC and also in UCDP-PRIO-GRID database with data for the period 1990-2005 every 5 years. Values for the intermediate years are interpolated. For the period 2006-2016 we have interpolated data of 2005 with the annual growth rate obtained from data on GCP at the grid level provided by Kummu et al. (2018). In order to obtain values compatible with those from SEDAC for the period 1990-2005 (also adopted in UCDP-PRIO, hence considered as the most reliable data source), we have rescaled the GCP values from Kummu et al. (2018) in order to have a total GCP at the country level equal to the gross domestic product (GDP) in the WDI database from the World Bank (considering the previous calibration of gridded GCP data by SEDAC with GDP from WDI for the period 1990-2005). ${ }^{9}$

Within the category of social vulnerability, we also include the presence of mineral and fossil resources since there is empirical evidence that the presence of oil fields as well as mining activities might cause violent events and internal conflicts (Adano et al. 2012; Basedau et al. 2018; Bodea et al. 2016). In order to maintain the geographical resolution and the panel structure of the dataset we have first computed a dummy variable assuming value 1 if an exhaustible resource (coal, oil, natural gas, minerals) is exploited in an area located within the cell by comparing our grid shape

\footnotetext{
${ }^{9}$ GCP values provided by Kummu et al. (2018) are available for a grid resolution that is smaller than the scale adopted in our paper. Before calculating the annual growth rate, we have matched information from Kummu et al. (2018) with our shape file with grid resolution of $1^{\circ} \times 1^{\circ}$ and calculated an average GCP value compatible with 1990-2005 data.
} 
with information available from the georeferenced Data Basin Dataset; this allowed us to enrich the information provided by PRIO-GRID with data on localisation of infrastructures for intermediate transformation and transport (pipelines, refineries, etc.) that are often in areas when conflicts occur, as for instance in North Africa where several militia attacks broke out along pipelines and export terminals in Algeria and Libya during 2016. ${ }^{10}$

In addition, as for the case of rural land cover, we compute a time-variant variable that results from interacting the cell-based resource dummy with a time variant country-based variable representing the share of fossil fuels and minerals export value on total merchandise exports at the country level taken from WDI. This operationalization allows two advantages. First, resource-related variables can be retained into econometric estimations applied to panel structure with cell-based fixed effects. Second, the relative magnitude of economic interests surrounding each resource basin or infrastructure is considered.

Finally, in order to account for democracy and more in general to the quality of institutions at the country level, we have considered Political Risk Services Index (PRI) provided by the PRS Group as the most complete database covering the entire time span and all countries included in our analysis. In particular, the PRI database includes a homogeneous set of twelve indices measuring various dimensions of a country's political and socio-economic conditions (Government Stability, Socioeconomic Conditions, Investment Profile, Internal Conflict, External Conflict, Corruption, Military in Politics, Religious Tensions, Law and Order, Ethnic Tensions, Democratic Accountability, Bureaucracy Quality) from which we compute a composite index (hereafter referred to as PRS) obtained as a the average of the aforementioned dimensions with the exclusion of Internal and External Conflict. ${ }^{11}$ In addition, by combining the information on institutional quality with resource endowment and exploitation, we can also address the potential impact of a resource curse while controlling for the quality of institutions, according to most recent advancement in resource curse hypothesis contributions (Sarmidi et al. 2014).

\subsection{Robustness checks and estimation details}

Regarding the estimation procedure, our analysis is based on the routines developed in STATA by Belotti et al. (2017) under the command xsmle, which are based on quasi-maximum likelihood techniques described in Elhorst (2009) and LeSage and Pace (2009). ${ }^{12}$

\footnotetext{
${ }^{10}$ Information on fossil fuels and minerals basins (on-shore) in Data Basin Dataset are fully compatible with those used in PRIO-GRID.

11 Since the individual indices have different range of variation (i.g., the maximum numerical value is not homogeneous), we calculate the PRS composite index as the average of the normalized components. We have also checked the statistical significance of the quality of institutions by including one by one the single components (excluding conflicts) of the index and results remain quite stable for all components. Results are available upon request from the authors.

12 The dynamic specification among the available options in xsmle here adopted is dlag(1), with lagged dependent variable but no temporal lag for the spatially lag term $\boldsymbol{W} Y_{j t-1}$ since the estimated coefficient is not statistically significant.
} 
First, the parameters reported in the "Tables in the Appendix" have been estimated without the bias-correction (option leeyu) early proposed by $\mathrm{Yu}$ et al. (2008) that is available only for model without the endogenous dynamics following the Lee and $\mathrm{Yu}$ (2010) and $\mathrm{Yu}$ et al. (2012) procedure. Given that literature on conflicts highlights the key role played by persistency over time in line with the "conflict trap" theory, we considered the dynamic structure as compulsory to provide a model as much as complete as possible. As a robustness, we estimated models in Table 9 without including the lagged endogenous components, with and without the bias-correction. Given that in our case we have a large $\mathrm{N}$ and a relatively small T, according to Yu et al. (2008) the bias risk is mainly associated to parameters for the spatially lagged covariates and the value of variance. Given the equivalence in coefficients and variance, results reported in the paper are not biascorrected. Following Yu et al. (2008), even if coefficients are not biased, a dynamic spatial panel model is stable only when the sum of the parameters $\alpha$ and $\rho$, associated to the temporal lag and the spatial lag of the endogenous variable, is not greater than 1. Accordingly, we comment in the text marginal effects computed only on those models with the lowest combination of $\alpha+\rho$, while in the appendix all models are reported with the estimated coefficients. ${ }^{13}$

Second, given that the number of conflicts is a count variable, we have compared the results of our normal linear model with those of a model based on a Poisson distribution. Given that the spatial Durbin model includes both endogenous and exogenous spatial interaction effects, the extension of these concepts to count data models is not always straightforward. In fact, the introduction of endogenous interaction effects is quite controversial in classical count data models (Glaser 2017), the reason being that there is no direct functional relationship between the regressors and the dependent variable (but rather a relationship between the regressors and the conditional expectation of the response). Among the proposals available in literature we can mention Beger (2012) who, in order to model the counts of civilian deaths in the Bosnian war with a negative binomial regression model, included the spatially lagged dependent variable into the intensity equation using an exponential spatial autoregressive coefficient. A different possibility, considered for instance in the spatial autoregressive Poisson model (P-SAR) of Lambert et al. (2010), is to include into the intensity equation the spatially lagged conditional expectation (rather than the spatially lagged dependent variable). However, none of these different ways of including a spatial autoregressive structure into count regression models have found broad application so far. Instead, as pointed out in Glaser (2017), the introduction of exogenous interaction effects is straightforward also in count data models and raises no particular issues: spatially lagged regressors can be computed before the actual regression is performed and treated in the same way as the non-spatial ones. Accordingly, in order to verify the robustness of our results with respect to the distribution assumed by the model, we have exogenously weighted by the inverse distance matrix (with spectral normalisation in order to obtain results similar to those obtained with the spatial

\footnotetext{
${ }^{13}$ We have also checked for stability in parameters by performing the same regressions by using rownormalised weight matrixes, but results remain substantially unchanged.
} 
Durbin). However, both the AIC and the BIC strongly support the dynamic spatial Durbin model with respect to the Poisson one, thus pointing out the importance of including endogenous interactions even in a model that is not specifically designed to deal with count data. ${ }^{14}$

Third, we adopt a symmetrical matrix instead of a row normalised one for the following reasons. First, LeSage and Pace (2014) argue that in row normalisation is recommended if it is the economic behaviour of individuals that leads to row normalization. In our case, however, the behaviour of agents does not seem to fall into this category. Second, as pointed out in Kelejian and Prucha (2010), normalising the elements of a spatial weight matrix by a different factor for each row (as it is the case in the row normalisation) is likely to lead to misspecification problems, especially when an inverse distance matrix is assumed. It is important to acknowledge that in order to overcome this problem, various alternative normalization procedures have been proposed (Elhorst 2001; Kelejian and Prucha 2010; Ord 1975); these, unlike row normalization, lead to a weight matrix that is symmetric (so that it does not lose its economic interpretation in terms of distances) and such that the mutual proportions between the elements of $\boldsymbol{W}$ remain unchanged (Elhorst 2014). In our case we consider the inverse distance $\boldsymbol{W}$ without any ex-ante normalisation procedure because it is the only way to account for the fact that if a cell is surrounded by several other units characterised by a high number of conflicts, the contagious effect is high and the actual distance is crucial in shaping it. In order to check the robustness of our results with respect to the normalization of the weight matrix, we have estimated the models with an inverse distance row normalised matrix using the cut-offs of $250 \mathrm{~km}$ for the dependent variable and of $500 \mathrm{~km}$ for the covariates. However, as expected, the results with row normalised weights are not as significant as those obtained with the original matrix, and both the AIC and the BIC strongly recommend the symmetric inverse distance matrix rather than the row normalised one. ${ }^{15}$ Notice that all weight matrixes have been computed using QGIS software, since it is the software used for the construction of the grid and for the transformation of the dependent variable from punctual conflicts associated to specific coordinates into larger areas represented by our cells.

Fourth, tests for model fitting for comparison with other spatial model specifications, test for choosing the cut-off distance for $\boldsymbol{W}$ and $\boldsymbol{D}$, punctual estimates for SDM results with robustness tests, Hausman test for random versus fixed effects, collinearity robustness with Condition numbers, AIC and BIC values are all reported in "Appendix 2". Controls for potential influence of outlier values have been performed by applying the multivariate blocked adaptive computationally efficient outlier nominators (BACON) algorithm proposed by Billor et al. (2000). By applying the default percentile $(0.15)$ of the Chi squared distribution to be used as a threshold to separate outliers from non-outliers, we obtain 28 outliers. By performing the same regression dropping out these observations results remain stable. In addition, for the sake of simplicity we report estimates with the temporal lag structure of one year as the most appropriate in terms of model fitting performed

\footnotetext{
14 Results are available upon request from the authors.

15 Results are available upon request from the authors.
} 
by comparing AIC and BIC values. Results for models with alterative time lags are available upon request from the authors. In "Appendix 2", Table 8 has been used to select the best distance threshold in the spatial matrix for the effects of cell-based climate and socio-economic features on conflicts number. The SDM specification with the best AIC and BIC has been compared with the corresponding SAR and SLX versions with a Likelihood ratio test reported in the corresponding column.

Fifth, still regarding the procedure for the grid and the inverse distance matrixes construction, it is worth mentioning that the artificial grid has been designed in order to assign each cell to one specific country. For those cells belonging to different countries we have adopted two corrections. If a major portion of the area is included in one country, the cell is assigned to that country. On the contrary, if the area is equally distributed in different countries, we have artificially created a number of cells equal to the number of countries insisting on that area assigning a coordinate (latitude or longitude) differing by $0.25^{\circ}$. For what concerns the association of conflicts to cells, the UCDP-GED database allows a punctual geographical association with specific coordinates, differently from the PRIO GRID information that is based on coordinates associated to cells and not to points. Regarding the values associated to the social vulnerability, the linking method jointly adopted the ISO information for each country and the coordinates of the cell. For what concerns the climate related variables, they have been computed as average values given by a raster applied to the grid, where original values for both temperature and precipitations are at the $0.25^{\circ} \times 0.25^{\circ}$ grid level. A complete list of variables with main statistics and correlation matrix are provided in "Appendix 1".

Sixth, data for temperature and precipitations are on monthly basis as part of the joint project “African Flood and Drought Monitor" between Princeton University, ICIWaRM and UNESCO-IHP. Raw monthly values at the $0.25^{\circ}$ grid resolution scale are first transformed into $1^{\circ}$ resolution. Then, values of temperature and precipitations for each year and each cell are calculated as the average of monthly data. Changes over time (one and 5 years) are computed as average monthly changes (e.g., difference in temperature of January in year $t$ with respect to that of January in year $t-1$, computed for twelve months and then averaged for each year). Given that our dependent variable represents the total number of conflicts occurred over each year, short-term changes in climate related variables within the year cannot be matched with the exact moment the different conflicts occurred. Accordingly, the relative effect of changes in climatic variables can be addressed in a broad sense by lagging independent variables with respect to the dependent variable. In so doing, changes in climatic conditions can be assessed as driving factors of increasing conflicts in one cell without punctually disentangling the mechanisms (the indirect effects) induced by climate change. Alternative time lags and different time spans for medium-term changes have been tested. In the case of time lag, one-year lag results as the best model fit in terms of AIC and BIC values. Concerning time spans for climate-related variables, periods longer than 5 years substantially reduce the number of observations and reduce the model fit. Accordingly, 5 years span is the longest period to be accounted without losing statistical significance. 


\section{Results}

In what follows we discuss econometric results in terms of marginal effects obtained by three different models based on a dynamic SDM estimated with an MLE. In Eqs. (7), (8), (9) all variables in level are log-linearized while variation rates are expressed in the form of natural logarithm of the ratio between the final and the initial level. All models include cell specific $\left(\gamma_{i}\right)$ and year $\left(\delta_{t}\right)$ fixed effects in order to capture potential omitted variables effect. All variables with sub-script $i$ refer to cell-specific measures while sub-script $c$ refers to country-specific covariates. The first model setting considers the relation between number of conflicts and the geographical and social characteristics of each cell ${ }^{16}$ :

$$
\begin{aligned}
N C_{i t}= & \alpha N C_{i t-1}+\rho \sum_{j \neq i=1}^{n} w_{250 i j} N C_{j t}+\beta^{x} X_{i t}+\vartheta^{x} \sum_{j \neq i=1}^{n} d_{500 i j} X_{j t}+\beta^{z} Z_{i t-1} \\
& +\vartheta^{z} \sum_{j \neq i=1}^{n} d_{500 i j} Z_{j t-1}+\beta^{k} K_{c t}+\gamma_{i}+\delta_{t}+\varepsilon_{i t}
\end{aligned}
$$

The second model setting considers the relation between the number of conflicts and the geographical and social characteristics of each cell as well as changes occurring in the short-term for social dimension (represented by the GCP per capita growth rate) and climate variables. In both cases the optimal lag structure for variables is one year. Accordingly, the short-term change is calculated as the variation occurring at time $t-1$ w.r.t. the previous year (hereafter referred as $1 \mathrm{y}$ ). Model equation results as follows:

$$
\begin{aligned}
N C_{i t}= & \alpha N C_{i t-1}+\rho \sum_{j \neq i=1}^{n} w_{250 i j} N C_{j t}+\beta^{x} X_{i t}+\vartheta^{x} \sum_{j \neq i=1}^{n} d_{500 i j} X_{j t}+\beta^{z} Z_{i t-1} \\
& +\vartheta^{z} \sum_{j \neq i=1}^{n} d_{500 i j} Z_{j t-1}+\beta^{z} \Delta^{1 y} Z_{i t-1}+\vartheta^{z} \sum_{j \neq i=1}^{n} d_{500 i j} \Delta^{1 y} Z_{j t-1}+\beta^{k} K_{c t}+\gamma_{i}+\delta_{t}+\varepsilon_{i t}
\end{aligned}
$$

The third model setting considers the relation between number of conflicts and the geographical and social characteristics of each cell as well as changes occurring in the one year (1y) for social dimension and in the medium-term for climate variables (calculated as the average value of yearly changes over the past 5 years starting from time $t-1$, hereafter referred as $5 \mathrm{y}$ ) in the form:

\footnotetext{
${ }_{16}$ In Eqs. (7)-(9) we refer to a set of $X$ variables when they are not temporally lagged and a set of $Z$ variables if they are one-year or five-year lagged, while set of $K$ variables are those country and not cellbased.
} 


$$
\begin{aligned}
N C_{i t}= & \alpha N C_{i t-1}+\rho \sum_{j \neq i=1}^{n} w_{250 i j} N C_{j t}+\beta^{x} X_{i t}+\vartheta^{x} \sum_{j \neq i=1}^{n} d_{500 i j} X_{j t}+\beta^{z} Z_{i t-1} \\
& +\vartheta^{z} \sum_{j \neq i=1}^{n} d_{500 i j} Z_{j t-1}+\beta^{z} \Delta^{1 y} Z_{i t-1}+\vartheta^{z} \sum_{j \neq i=1}^{n} d_{500 i j} \Delta^{1 y} Z_{j t-1} \\
& +\beta^{z} \Delta^{5 y} Z_{i t-1}+\vartheta^{z} \sum_{j \neq i=1}^{n} d_{500 i j} \Delta^{5 y} Z_{j t-1}+\beta^{k} K_{c t}+\gamma_{i}+\delta_{t}+\varepsilon_{i t}
\end{aligned}
$$

Table 1 summarizes variables description and data source used for econometric estimations of models expressed in Eqs. (7), (8), (9). Tables 2, 3 and 4 contain marginal effects estimated; for both short and medium-term climate change horizons we obtain direct and indirect short and long-term effects. In order to simplify the interpretation of results, we provide an overall picture in Fig. 1 summarizing the linkages related to direct and indirect effects associated to changes in climate conditions occurred in the short-term (1y) and in the medium-term (5y).

According to Elhorst (2012) we define as geographical spillovers those spatial interactions representing the effects induced by climate change occurring in surrounding areas, among which we can for instance include migration flows as suggested by Buhaug (2015). The same model linkages related to spillovers apply to all exogenous variables that are spatially lagged. The persistency of the phenomenon due to direct and indirect effects is vehiculated by the time lag applied to the dependent variable.

Before commenting on marginal effects related to socio-economic vulnerability and climate conditions, we focus on two main results (not reported in Tables for marginal effects but available in "Appendix 2" in all Tables reporting short-term estimates of coefficients) that allow comparing our findings with well-established results in literature, thus providing some measures of robustness of the methodological approach here developed.

First, we find evidence on the key role played by contagion, as the estimated spatial $\rho$ (associated with the number of conflicts in neighbouring cells) is always positive and statistically significant. It is worth mentioning that by focusing on the number of events we differentiate with respect to Harari and La Ferrara (2018) whose analysis is on the occurrence of at least one event per year. This explains why the cut-off distance for contagion in our case is larger measuring a maximum of $311 \mathrm{~km}$ instead of $180 \mathrm{~km}$.

Second, we find that persistency over time (represented by the coefficient $\alpha$ ) according to the conflict trap hypothesis (Collier 2003; Ide et al. 2014; Maystadt et al. 2015) is a key element explaining the number of conflicts, confirming that once a region has experienced violent events, ceteris paribus it is more at risk of further conflicts. This enhances the robustness of the choice for adopting a dynamic structure of the spatial panel estimation.

According to Yu et al. (2008), in a spatial dynamic panel data model with large $\mathrm{N}$ and large $\mathrm{T}$ the sum of absolute values of parameters representing persistency and contagion, $\alpha$ and $\rho$ respectively in our specification, should be no larger than 1 if the 
Table 1 Variable description and original source

\begin{tabular}{|c|c|c|}
\hline Variable & Description & Source \\
\hline \multicolumn{3}{|c|}{ Cell-based/time variant } \\
\hline $\mathrm{NC}$ it & Number of conflicting events & UPPSALA-UCDP \\
\hline Temp it-1 & Temperature (yearly average value, ${ }^{\circ} \mathrm{C}$ ) & AFDM \\
\hline Prec it-1 & Precipitation (yearly average value, $\mathrm{mm} /$ day) & AFDM \\
\hline SPI it-1 & SPI-12 (yearly average value, index) & AFDM \\
\hline GCP it-1 & Gross Cell Product (Th. US\$ PPP constant 2005) & SEDAC-WDI \\
\hline Pop it-1 & Population (number) & SEDAC-HYDE \\
\hline $\begin{array}{l}\text { D1y-GCP-PC it- } \\
1\end{array}$ & One-year var of GCP per capita w.r.t. $\mathrm{t}-1(\%)$ & Authors' elaboration \\
\hline D1y-Temp it-1 & One-year var of temperature w.r.t. $\mathrm{t}-1(\%)$ & Authors' elaboration \\
\hline D1y-Prec it-1 & One-year var of precipitation w.r.t. $\mathrm{t}-1(\%)$ & Authors' elaboration \\
\hline D5y-Temp it-1 & Average $5 y$ var of temperature in $t-1(\%)$ & Authors' elaboration \\
\hline D5y-Prec it-1 & Average $5 y$ var of precipitation in $\mathrm{t}-1(\%)$ & Authors' elaboration \\
\hline Av5y-SPI it-1 & Average SPI-12 in the past $5 y$ at $t-1$ (index) & Authors' elaboration \\
\hline \multicolumn{3}{|c|}{ Cell-based/time invariant } \\
\hline Resource-D i & Presence of mineral and fossil fuel resources (dummy) & Data Basin Dataset \\
\hline Rural-D i & Presence of rural areas (dummy) & Global Land Cover \\
\hline Drought i & Drought Severity (index) & $\begin{array}{l}\text { Aqueduct Water } \\
\text { Risk }\end{array}$ \\
\hline Flood i & Flood Occurrence (index) & $\begin{array}{l}\text { Aqueduct Water } \\
\text { Risk }\end{array}$ \\
\hline
\end{tabular}

Country-based/time variant

\begin{tabular}{|c|c|c|}
\hline Agri VA ct & Value Added in Agriculture w.r.t. total VA (\%) & WDI-World Bank \\
\hline FF-Min exp ct & Export Value for exhaustible resources w.r.t. Merch Exp (\%) & WDI-World Bank \\
\hline Inst-PRS ct & PRS synthetic institutional quality (index) & PRS Group Dataset \\
\hline Inst-Gov-Eff ct & Government effectiveness (index) & PRS Group Dataset \\
\hline Inst-Law ct & Law and order (index) & PRS Group Dataset \\
\hline No. y indep ct & Number of years from colonial independence (number) & CIA \\
\hline \multicolumn{3}{|c|}{ Cell-based/time variant interaction terms } \\
\hline Agricult it & Rural-D $\times$ Agri VA & Authors' elaboration \\
\hline Resources it & Resource-D $\times$ FF-Min exp & Authors' elaboration \\
\hline Int-Resources it & Resources it $\times$ Institutional quality indices & Authors' elaboration \\
\hline D1y-Temp it-1 dr & One-year var of temp w.r.t. $\mathrm{t}-1^{*}$ in drought risk cell & Authors' elaboration \\
\hline D1y-Prec $_{\text {it-1 }}$ rur & D1y-Prec it-1 $\times$ Rural-D i & Authors' elaboration \\
\hline D1y-Prec it-1 dr & D1y-Prec it-1 $\times$ Drought i & Authors' elaboration \\
\hline D1y-Prec $_{\text {it-1 }}$ fl & D1y-Prec it-1 $\times$ Flood i & Authors' elaboration \\
\hline $\mathrm{SPI}_{\text {it-1 }}$ rur & SPI-12 × Rural-D i & Authors' elaboration \\
\hline SPI ${ }_{\text {it-1 }}$ dr & SPI-12 $\times$ Drought i & Authors' elaboration \\
\hline SPI ${ }_{\text {it-1 }} \mathrm{fl}$ & SPI-12 $\times$ Flood i & Authors' elaboration \\
\hline D5y-Temp it-1 dr & D5y-Temp it- $1 \times$ Drought i & Authors' elaboration \\
\hline D5y-Prec it-1 rur & D5y-Prec it-1 $\times$ Rural-D i & Authors' elaboration \\
\hline D5y-Prec it-1 dr & D5y-Prec it-1 $\times$ Drought i & Authors' elaboration \\
\hline
\end{tabular}


Table 1 continued

\begin{tabular}{lll}
\hline Variable & Description & Source \\
\hline D5y-Prec it-1 fl & D5y-Prec it-1 × Flood i & Authors' elaboration \\
Av5y-SPI it-1 rur & Av5y-SPI it-1 $\times$ Rural-D i & Authors' elaboration \\
Av5y-SPI it-1 dr & Av5y-SPI it-1 $\times$ Drought i & Authors' elaboration \\
Av5y-SPI it-1 fl & Av5y-SPI it-1 $\times$ Flood i & Authors' elaboration \\
\hline
\end{tabular}

Table 2 Marginal effects of climate and socio-economic conditions

\begin{tabular}{|c|c|c|c|c|}
\hline & $\begin{array}{l}\text { (1) } \\
\text { Direct }\end{array}$ & $\begin{array}{l}\text { (1) } \\
\text { Indirect }\end{array}$ & $\begin{array}{l}\text { (6) } \\
\text { Direct }\end{array}$ & $\begin{array}{l}\text { (6) } \\
\text { Indirect }\end{array}$ \\
\hline \multicolumn{5}{|l|}{ Short term } \\
\hline GCP it-1 & $-0.020 * * *$ & -0.015 & 0.005 & 0.090 \\
\hline Pop it-1 & $0.051 * * *$ & 0.082 & 0.034 & -0.299 \\
\hline Temp it-1 & $0.887 * * *$ & -0.480 & $1.015 * *$ & 0.285 \\
\hline Prec it-1 & $0.016 *$ & -0.044 & $0.029 * * *$ & 0.104 \\
\hline SPI it-1 & $-0.018 * * *$ & 0.028 & -0.022 & -0.032 \\
\hline Resources it & -0.000 & -0.000 & 0.001 & -0.004 \\
\hline Int-Resources it & $-0.001 * *$ & -0.002 & -0.000 & 0.001 \\
\hline Agricult it & $0.113 * * *$ & 0.154 & 0.149 & -0.614 \\
\hline $\mathrm{Nr}$ year from indep ct & $-0.005 * *$ & -0.007 & & \\
\hline Inst-Law\&Order ct & & & -0.000 & 0.002 \\
\hline Inst-PRS ct & & & -0.001 & 0.005 \\
\hline \multicolumn{5}{|l|}{ Long term } \\
\hline GCP it-1 & -0.033 & 0.088 & 0.010 & 0.024 \\
\hline Pop it-1 & 0.077 & -0.312 & 0.088 & -0.170 \\
\hline Temp it-1 & 1.604 & -1.443 & 2.238 & -1.672 \\
\hline Prec it-1 & 0.033 & 0.054 & 0.068 & -0.012 \\
\hline SPIit-1 & -0.033 & -0.009 & -0.050 & 0.024 \\
\hline Resources it & -0.000 & 0.000 & 0.003 & -0.003 \\
\hline Int-Resources it & -0.002 & 0.008 & -0.001 & 0.001 \\
\hline Agricult it & 0.167 & -0.614 & 0.337 & $-0.485^{* *}$ \\
\hline $\mathrm{Nr}$ year from indep ct & -0.007 & 0.030 & & \\
\hline Inst-Law\&Order ct & & & -0.001 & 0.001 \\
\hline Inst-PRS ct & & & -0.001 & 0.004 \\
\hline
\end{tabular}

$* p<0.1, * * p<0.05, * * * p<0.01$ 
Table 3 Marginal effects of 1y changes in climate and socio-economic conditions

\begin{tabular}{|c|c|c|c|c|}
\hline & $\begin{array}{l}(1) \\
\text { Direct }\end{array}$ & $\begin{array}{l}\text { (1) } \\
\text { Indirect }\end{array}$ & $\begin{array}{l}(3) \\
\text { Direct }\end{array}$ & $\begin{array}{l}(3) \\
\text { Indirect }\end{array}$ \\
\hline \multicolumn{5}{|l|}{ Short term } \\
\hline GCP it-1 & $-0.027 * * *$ & -0.152 & $-0.027 * * *$ & -0.189 \\
\hline D1y-GCP-PC it-1 & $0.150 * * *$ & 3.143 & $0.159 *$ & 4.411 \\
\hline Pop it-1 & $0.059 * * *$ & 0.468 & $0.061 * * *$ & 0.645 \\
\hline Temp it-1 & $0.291 * * *$ & -3.893 & $0.284 * *$ & -5.284 \\
\hline D1y-Temp it-1 & $1.693 * * *$ & 5.410 & $1.705 * * *$ & 6.954 \\
\hline D1y-Temp it-1 dr & $-0.408 * * *$ & -0.599 & $-0.408 * * *$ & -0.618 \\
\hline Prec it-1 & $0.012 * *$ & -0.012 & $0.012 * *$ & -0.032 \\
\hline SPI it-1 & $-0.017 * * *$ & 0.117 & $-0.027 * * *$ & 0.261 \\
\hline SPI it-1 dr & & & 0.005 & -0.041 \\
\hline Resources it & $0.003 * * *$ & 0.020 & $0.003 * * *$ & 0.026 \\
\hline Int-Resources it & $-0.001 * * *$ & -0.009 & $-0.001 * * *$ & -0.012 \\
\hline Agricult it & $-0.002 * * *$ & -0.015 & $-0.002 * * *$ & -0.021 \\
\hline $\mathrm{Nr}$ year from indep ct & $0.100 * * *$ & 0.768 & $0.106^{* * * *}$ & 1.092 \\
\hline Inst-PRS ct & $-0.011 * * *$ & -0.086 & $-0.012 * * *$ & -0.121 \\
\hline \multicolumn{5}{|l|}{ Long term } \\
\hline GCP it-1 & -0.053 & 0.057 & -0.041 & 0.039 \\
\hline D1y-GCP-PC it-1 & 0.257 & -0.547 & 0.171 & -0.556 \\
\hline Pop it-1 & 0.118 & -0.130 & 0.089 & -0.114 \\
\hline Temp it-1 & $0.658 *$ & 0.004 & 0.647 & 0.067 \\
\hline D1y-Temp it-1 & 3.415 & -3.075 & 2.662 & -2.269 \\
\hline D1y-Temp it-1 dr & -0.832 & 0.642 & -0.660 & 0.471 \\
\hline Prec it-1 & 0.027 & -0.018 & 0.021 & -0.007 \\
\hline SPI it-1 & -0.038 & 0.014 & -0.048 & -0.004 \\
\hline SPI it- $1 \mathrm{dr}$ & & & 0.007 & 0.003 \\
\hline Resources it & 0.005 & -0.006 & 0.004 & -0.005 \\
\hline Int-Resources it & -0.002 & 0.003 & -0.002 & 0.002 \\
\hline Agricult it & -0.004 & 0.004 & -0.003 & 0.004 \\
\hline $\mathrm{Nr}$ year from indep ct & 0.190 & -0.224 & 0.145 & -0.202 \\
\hline Inst-PRS ct & -0.022 & 0.024 & -0.017 & 0.023 \\
\hline
\end{tabular}

$* p<0.1, * * p<0.05, * * * p<0.01$

weight matrix is row normalised. Accordingly, even if we adopt a symmetrical matrix and we have $\mathrm{N}$ much larger than $\mathrm{T}$, we consider as stable only those models with $|\alpha|+|\rho|$ with the lowest values. ${ }^{17}$

17 Tables 2, 3, and 4 report marginal effects computed only on these models while parameter estimates for all models are reported in Tables 9, 10, 11 in "Appendix 2". The number of the column in Tables 2, 3 , and 4 corresponds to the number of the model in Tables 9, 10, 11 . 


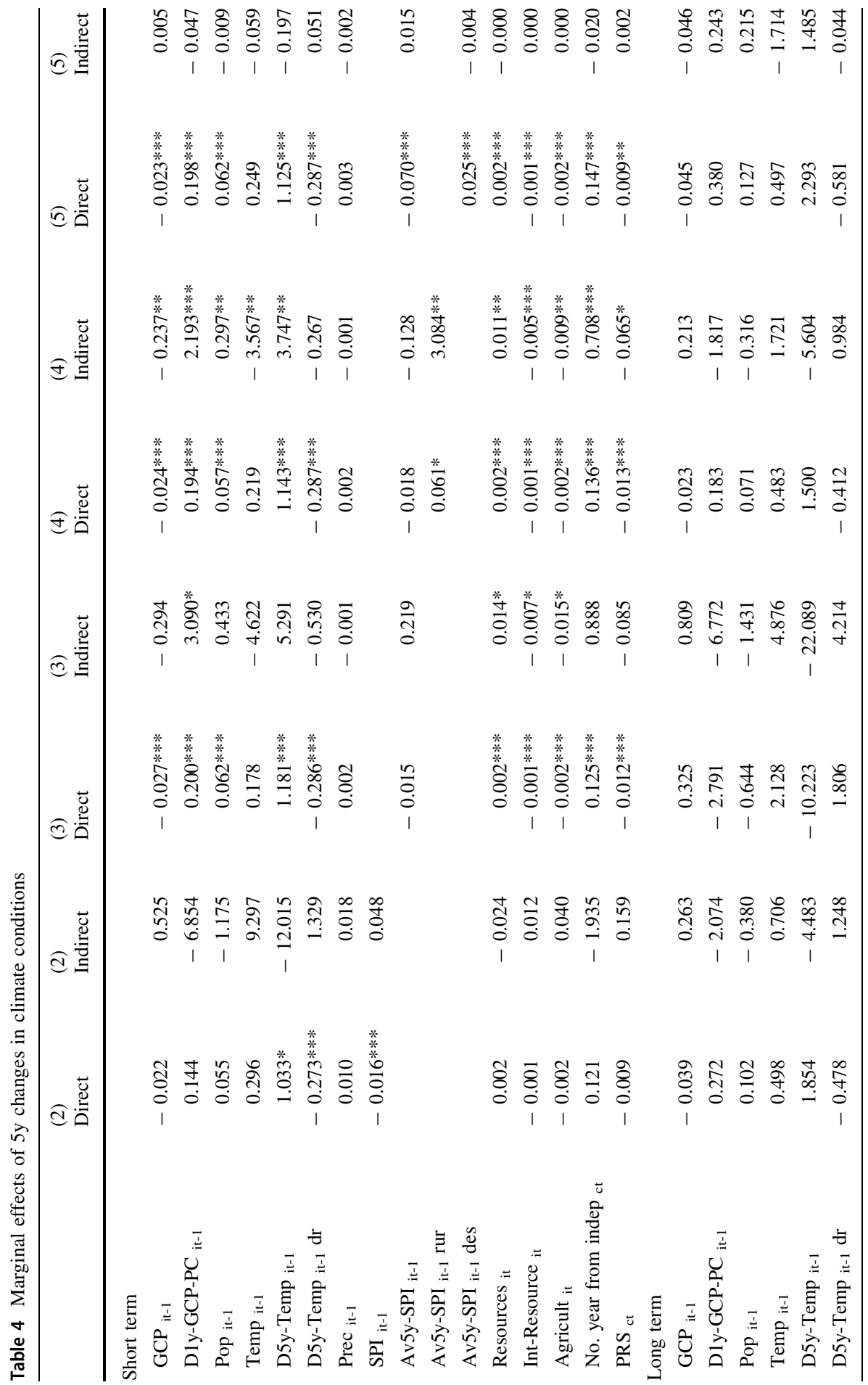




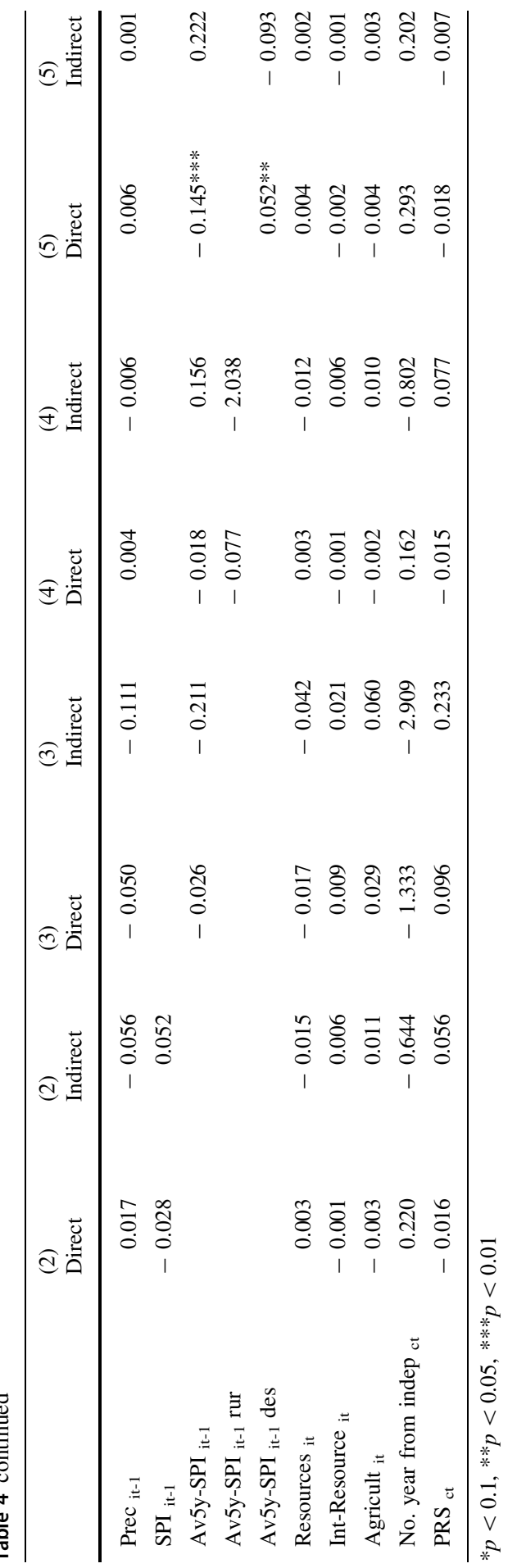




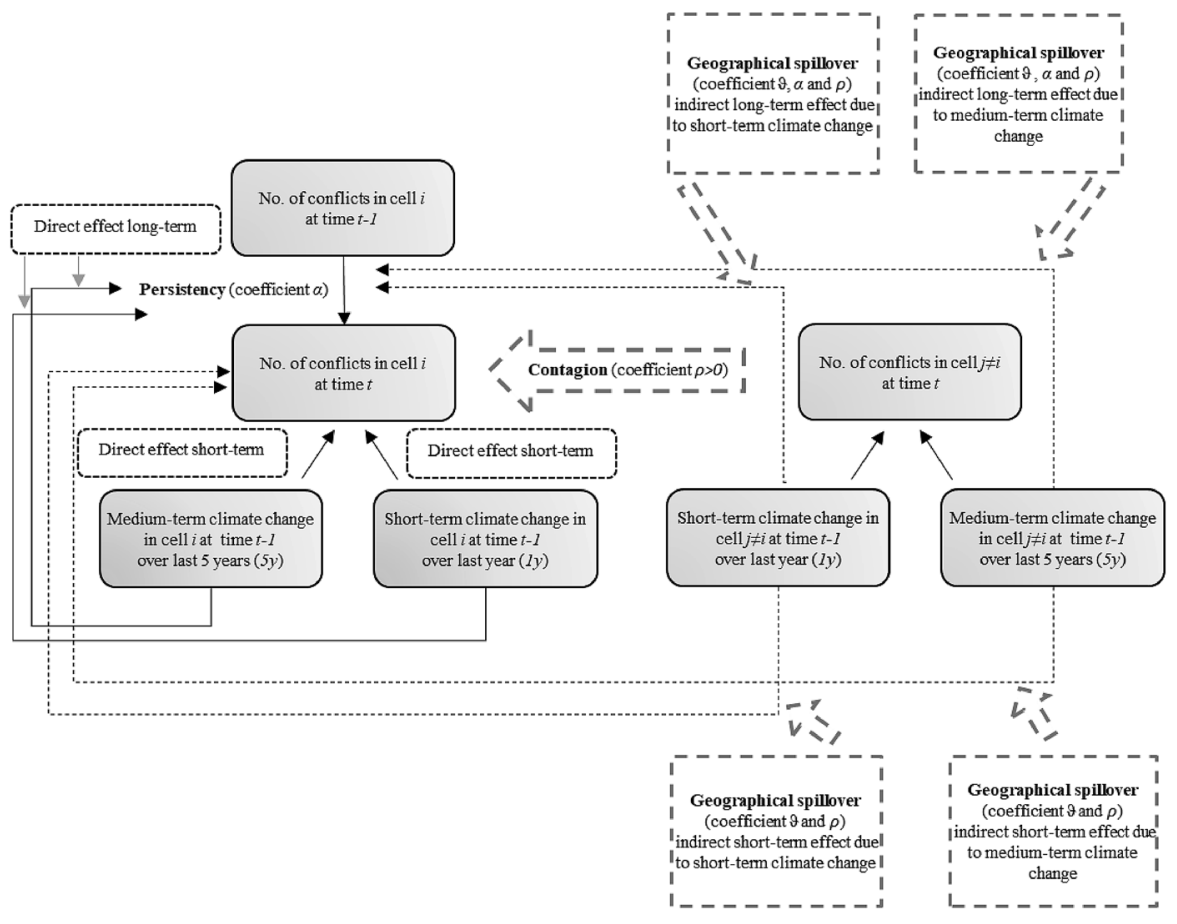

Fig. 1 Model framework

Let us start the discussion on marginal direct and indirect effects by examining the role of socio-economic vulnerability conditions. Looking at the impact of cell product (GCP), the direct effect has a negative sign meaning that areas with higher income are less likely to be involved in conflicting episodes, confirming findings in Busby et al. (2014). On the contrary, a relatively higher population count has a positive effect on number of conflicts. This may be expected, since ceteris paribus the number of conflicts is likely to be greater in highly populated places.

The indirect effect of GCP level is significant only in the short-term when considering the $5 y$ variation of climatic conditions (Table 4), while in the other specifications is never significant.

In order to better capture the role of income, in Tables 3 and 4 we also account for the impact of changes in the growth rate of GCP per capita and, in contrast to what happens in terms of GCP in level, the direct effect (when significant) is always positive. The indirect effect related to GCP per capita growth is positive in the shortterm, and it is statistically significant only when 5y climate change variation is included (Table 4), revealing that an increase in the GCP per capita in the neighbouring cells occurred in the previous year increases the number of conflicts in the cell itself. This result together with those described for the indirect effects associated with GCP in levels could be interpreted as a sign of the negative impact associated with increasing inequality in income distribution. A higher GCP level in cell $i$ is a sign of reduced socio-economic vulnerability and is negatively correlated 
with conflicts. On the contrary, if neighbouring cells are experiencing a higher increase in income per capita growth w.r.t. to cell $i$, this would imply an increase in income inequality that in turn could cause grievance leading to reprisals and potential violent actions to reduce inequality (Barnett and Adger 2007; Koubi et al. 2012).

As a general remark, in this modelling specification we find that indirect effects (when significant) exceed in absolute term the magnitude of the correspondent direct effect. A possible explanation of this empirical evidence is provided by the cumulative effects over space through channels that are not directly controlled in the regression (migration flows above all). According to LeSage and Dominguez (2012), the scalar summary measure for the indirect impacts cumulates many small impacts on a large number of cells in the sample, leading to a final effect where the spillover impacts are larger in magnitude than the direct impacts. This is explained by the fact that, although spillovers are second-order effects and are smaller in absolute term, by cumulating such smaller effects over cells they appear large in the scalar summary measures.

Another element in the overall picture of the role of socio-economic vulnerability is the quality of institutions, represented here by a country-based index of political stability (PRS). According to main findings, we obtain a negative and statistically significant coefficient meaning that those cells located in countries that are politically stable and with democratic institutions are less affected by conflicting events (Adano et al. 2012). Given that variables representing the quality of institution are country-based, we have tested an additional element for the socioeconomic vulnerability dimension represented by political exclusion of ethnic groups (Schleussner et al. 2016; von Uexküll et al. 2016). We have computed a cellbased time variant variable combining two statistical sources, the Geo-referenced of ethnic groups (GREG) dataset provided by Weidmann et al. (2010) and the Ethnic Power Relations (EPR) Core Dataset 2018 (Vogt et al. 2015). Surprisingly, ethnic fractionalisation is not significant in impacting on conflicts in our dataset, perhaps because ethnic features explain conflicts (and their strength and violence) only where conflicts arise (given the punctual geographical scale adopted), while they are less powerful in explaining why violent conflicts occur in some places while in others no conflicts are registered. ${ }^{18}$

Moving to the impact of agriculture, the direct effect is always negative (with the exception of Table 2 in which changes in climate are not introduced) meaning that ceteris paribus those areas with a higher specialisation in agricultural activities are well equipped with resources able to ensure human livelihood. At the same time, as

\footnotetext{
18 First, we have considered the Geo-referenced of ethnic groups (GREG) dataset provided by Weidmann et al. (2010). In GREG, data are divided into zones (polygons) that do not perfectly match our cells. By merging the two shape files (our grid resolution with the polygons) we have associated to each cell the number of ethnic groups living on that territory. Given that our cells may include a portion of different polygons, we have included the total number of ethnic groups dropping out duplicates. Then, we have built a variable (time variant and country based) representing the event of a shock in the equilibrium (and or bargaining power) of different groups in managing the political power, from the Ethnic Power Relations (EPR) Core Dataset 2018 (Vogt et al. 2015). In order to represent the entity of the shock we compute the number of changes in ethnic groups' conditions in each year (as a proxy of the turbulence in political power management and distribution). The final cell-based time-variant variable is given by the interaction of these two elements. Results for this robustness check are available upon request from the authors.
} 
shown in Fjelde and von Uexküll (2012) these areas are also the most vulnerable to changes in climate conditions. Accordingly, if agricultural productivity would be substantially harmed by weather conditions, the resilience capacity of communities could be destroyed, resource availability would be reduced, and the probability of conflicts could increase.

Let us now focus on the role of changes in climate conditions in explaining conflicts. To this end, Fig. 2 shows a summary of the main effects (in terms of temperature change and the SPI index, which is by construction a change measure of precipitations) in the case of short (1y) and medium-term (5y), as from Tables 3 and 4 , respectively. We can interpret $1 \mathrm{y}$ variations as conjunctural anomalies in climate conditions (a heat wave, an extreme drought or an excess in rainfall confined to one single year) and 5y variations as more persistent changes in conditions (a prolonged drought or a stable increase in temperature levels over the past 5 years). Models reported in Tables 3 and 4 satisfy the stability condition suggested by $\mathrm{Yu}$ et al. (2008) for spatial dynamic panels. These models correspond to marginal effects that are statistically significant for temperature and SPI related indices, while marginal effects of precipitation per se are not different from zero. This is hardly surprising if we recall that the SPI is based on the standard deviation from expected value of rainfalls in each period. As an example, if rainfalls are scarce in a period of the year without agricultural activities, this event can be less disruptive than abundant (or excessive) rainfalls during the growing season that might bring more severe harvest losses than water scarcity. Accordingly, it is reasonable that precipitations per se are meaningless for armed conflicts, while deviation from the seasonal average has a higher explanatory power.

We first examine the role of temperature changes. The direct effect is always positive in line with O'Loughlin et al. (2012). More precisely, a 1\% increase in 1y temperature change in a cell produces an increase in $1.7 \%$ in the number of conflicts. Differently from previous studies, when considering spatial spillovers we find that when temperature increases in areas already facing drought, there is a reduction in number of events by around $0.4 \%$. This specific result might capture different mechanisms. First, very drought-prone areas are generally characterised by low population density. Second, a temperature increase in already dry regions might force people to move, reducing internal source of conflicts. Third, according to Adano et al. (2012), in environmentally fragile areas farmers and shepherds do not engage in violent conflict during a time of scarcity but during periods of plenty.

Turning to the indirect effect of $1 \mathrm{y}$ temperature change over the short-term, there is no empirical evidence of a spillover effect. The statistically significant coefficients in the SDM specification allows accounting for spatial correlation in covariates, but the marginal effect of indirect mechanisms is negligible.

Once a medium-term horizon is adopted, the strength of direct and indirect effects changes with respect to a short-term perspective. The increase in temperature over 5 years has a slightly lower direct impact than in the short-term with $1.2 \%$ increase in the number of conflicts. In the same line of short-term results, if temperature changes occur in already dry lands, the direct effect is negative. The greatest difference relies on indirect effects that in model 4 of Table 4 are now statistically significant and of large magnitude. Such spillover effect reveals that 


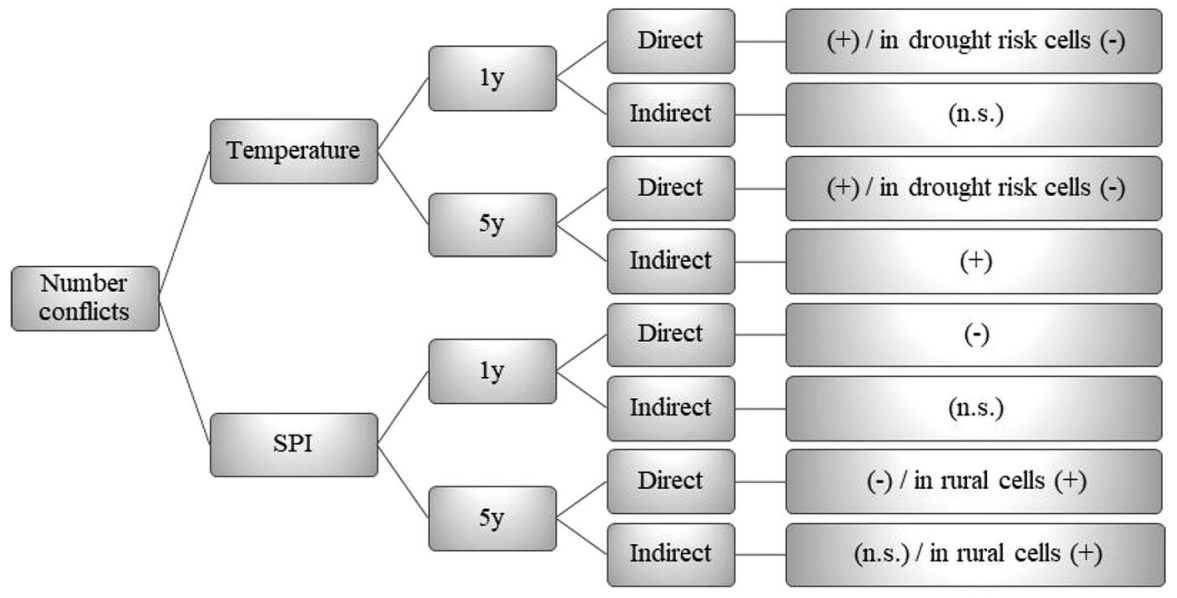

Note: the direction of the effect is in parentheses, while after / is commented the marginal effect computed on the interaction term.

Fig. 2 The strength of climate-conflict nexus from dynamic spatial econometric results

when accounting for what happened during the past 5 years, if neighbouring cells experienced prolonged temperature increases, this implies that a $1 \%$ increase in temperature change would bring to a $3.7 \%$ increase in the number of conflicts in cell $i$.

As a general remark, temperature changes strongly influence the number of conflicts when the spatial dimension is modelled. Accordingly, our modelling framework reveals that the introduction of spatial spillovers increases substantially the explanatory power of temperature rise in driving conflicts, in contradiction with those studies assigning a weak role of climate change in explaining conflict occurrence. $^{19}$

When considering the SPI-12 as a precipitation-based indicator for highlighting the specific role of drought, we find additional elements revealing the crucial role of changes in climate conditions in defining the dimension and strength of violence in Africa.

\footnotetext{
19 As a robustness check we have estimated models in Tables 10 and 11 in the "Appendix 2" with and without climate change related variables in order to test how relevant are climatic conditions with respect to other drivers of conflicts in order to compare model fit. Although Mach et al. (2019) in a structured judgments of experts analysis recently show that climatic variables are less relevant than other elements (as for instance socio-economic conditions) in explaining armed conflicts, from our empirical evidence based on the African continent over the period 1990-2016 we cannot reject the null hypothesis of omitted variables since model fit improves when including climate variables (by comparing AIC and BIC values). In addition, we have tested to which extent the introduction of spatial spillovers influences the statistical significance of coefficients associated to climate change variables by comparing a linear model based on a panel fixed effects with a spatial Durbin. The coefficients for temperature changes are the most influenced since their statistical significance improves with spatial lagged covariates and the AIC and BIC values favour the spatial Durbin specification. Results on these robustness checks are available upon request from the authors.
} 
At the general level, results confirm that deviation in precipitation levels directly influence conflicts. If a cell has experienced a period of drought in the previous year, the probability of having a higher number of conflicts increases by an average $0.02 \%$. When considering a medium-term perspective, if the cell experienced a prolonged period of drought (over the past 5 years) the direct effect is larger than in the $1-y$ case with an elasticity equal to $0.07 \%$ (model 5 in Table 4).

Additionally, we find that changes in precipitation levels have heterogeneous impacts according to the specific geographical features of the cell under scrutiny, revealing how crucial is the detailed characterization of the areas. If the SPI- 12 index presents a positive value for the past 5 years, it means that rainfall is continuously greater than expected. This provokes an increase in the number of conflicts if the cell is specialised in agricultural productivities. If the climate conditions in the cell are characterised by larger precipitations than expected, there is a higher risk of harvest destruction and a consequent resource scarcity constraint in areas not resilient and with poor adaptability at least in the medium term. Together with the direct impact, in a medium-term horizon there emerges a high indirect impact related to changes in SPI occurred in neighbouring cells characterised by agricultural activities. In line with results related to temperature changes, spillover effects reveal that there is a cumulated impact associated to food availability that might force people to migrate and increase competition in resource availability in other cells bringing to an increased number of conflicts.

\section{Conclusions and policy implications}

In this paper we conduct a spatially disaggregated analysis of the determinants of armed conflicts in Africa over the period 1990-2016 where spatial interactions are key factors explaining the multiple direct and indirect linkages occurring at the local and global level. The empirical analysis tries to simultaneously consider different causes of conflicts in order to better disentangle the specific role played by changes in weather conditions in impacting the vicious cycle of violence. By also accounting for the influence of dynamic persistency, we present several novel elements contributing to the literature on the nexus between climate and conflict.

First, our results provide evidence on the key role played by contagion. Differently from other grid-based studies that focus on the probability of conflict to occur or not, by quantifying the number of violent events per year we find that the cut-off distance substantially reducing the propagation of violence is higher, arriving at a maximum $311 \mathrm{~km}$ distance.

Second, we find a strong link between an increase in temperature and conflict that is robust with respect to different specifications and to the direct and indirect geographical pathways by which temperature affects conflict levels in a given area. The increase in temperature particularly over a medium-term horizon seems to give an impulse to violence, and this nexus is strongly reinforced by what occurs in neighbouring cells. This can be interpreted as an indirect effect associated to migration flows occurring in surrounding areas mostly affected by adverse climatic conditions. The policy implication directly linked to this result is the necessity to bring into the research agenda the analysis of interstate and internal migration flows 
at a geographically disaggregated scale together with a deeper investigation on causes of migration including changes in climate conditions, given the peculiar vulnerability of the African continent.

Third, while the role of punctual rainfall changes is not negligible, a substantial increase in drought conditions or the occurrence of excessive precipitations with respect to the average over a medium-term horizon, as represented by the SPI-12 index, reinforce the occurrence of conflicting events. In general, the marginal effects are smaller than those related to temperature, but indirect impacts are particularly large for neighbouring cells dedicated to agricultural activities. In accordance with other georeferenced studies focused on selected areas (e.g. Ethiopia, Kenya, and Uganda in Raleigh and Kniveton 2012), the unexpected increase in yearly average rainfalls raises conflicts in rural areas, suggesting that within the African continent, more than precipitation per se it is more appropriate to analyse the connection between changes in weather condition and resilience of local areas (Maystadt et al. 2015).

At a general level, our findings confirm that armed conflicts have a strong and complex local dimension that needs to be carefully considered when designing policy interventions. Action coordination is necessary both at the geographical scale and across different development and environment dimensions, since the causal linkages and feedback loops occurring in this complex framework might reduce or even nullify positive effects arising from single interventions. Rationalizations for particular linkages between weather conditions and violence are of course only suggestive of possible causes. The crucial role played by spatial spillovers in increasing the impact of changes in climatic conditions on conflict magnitude implies that in the analysis of hotspots, especially in scenario building, projections on the role played by temperature change or precipitation variations on occurrence and strength of conflicts should include the role of geographical spillovers, as we can expect the resulting number of projected conflicts to be rather higher than in the case of neglecting the role of spatial correlation. This is also reinforced by the relatively large buffer defining the contagion effect concerning the conflict propensity itself as already discussed.

Cross-border and persistent impacts across time and space of weather conditions should drive the policy discourse into a tightening dialogue on cross-cutting fields and interventions in two main directions: first, adaptation actions for reducing vulnerability to weather instability and long-term changes should be designed at a local scale but coordinated among wider areas; second, specific actions for impeding contagion should include peacekeeping programmes that could break the vicious cycle of violence while reinforcing those projects aiming at protecting local communities from negative impacts from changes in climatic conditions.

Acknowledgements Financial support from the Italian Ministry of Education, University and Research (Grant No. PRIN2017) (Scientific Research Program of National Relevance 2017 "Innovation for global challenges in a connected world: the role of local resources and socio-economic conditions") is gratefully acknowledged. Comments from participants to the 66th Annual North American Meetings of the Regional Science Association International (NARSC), November 2019 in Pittsburgh, USA are appreciated. We are indebted with the Editor and two anonymous reviewers since their comments and suggestions received on the previous versions of the paper were particularly insightful. The usual disclaimers apply. 
Open Access This article is licensed under a Creative Commons Attribution 4.0 International License, which permits use, sharing, adaptation, distribution and reproduction in any medium or format, as long as you give appropriate credit to the original author(s) and the source, provide a link to the Creative Commons licence, and indicate if changes were made. The images or other third party material in this article are included in the article's Creative Commons licence, unless indicated otherwise in a credit line to the material. If material is not included in the article's Creative Commons licence and your intended use is not permitted by statutory regulation or exceeds the permitted use, you will need to obtain permission directly from the copyright holder. To view a copy of this licence, visit http:// creativecommons.org/licenses/by/4.0/.

Funding Open access funding provided by Università degli Studi Roma Tre within the CRUI-CARE Agreement.

\section{Appendices}

\section{Appendix 1}

See Tables 5, 6 and 7 and Figs. 3, 4, 5 and 6.

Table 5 Main statistics

\begin{tabular}{llllll}
\hline Variable & Nr Obs & Mean & SD & Min & Max \\
\hline NC it & 91,854 & 0.38 & 3.81 & 0 & 248.00 \\
GCP it & 91,854 & 601,973 & 3023,916 & 0 & $120,000,000$ \\
D1y-GCP-PC it & 88,452 & 0.04 & 0.04 & -0.94 & 0.68 \\
Pop it & 91,854 & 256,176 & 716,349 & 0 & $27,000,000$ \\
Temp it & 91,854 & 25.18 & 3.55 & 6.63 & 34.28 \\
D1y-Temp it & 88,452 & 0.00 & 0.03 & -0.29 & 0.71 \\
D5y-Temp it & 71,442 & 0.00 & 0.01 & -0.08 & 0.20 \\
Prec it & 91,854 & 1.93 & 1.74 & 0 & 13.33 \\
D1y-Prec it & 88,452 & 0.01 & 0.36 & -3.00 & 2.95 \\
D5y-Prec it & 71,442 & 0.00 & 0.08 & -0.66 & 0.55 \\
SPI it & 91,854 & 0.00 & 0.97 & -3.72 & 3.72 \\
Av5y- SPI it & 71,442 & 0.06 & 0.58 & -3.72 & 3.69 \\
Resource-D i & 91,854 & 0.23 & 0.42 & 0 & 1.00 \\
Rural-D i & 91,854 & 0.11 & 0.31 & 0 & 1.00 \\
Drought i & 91,854 & 2.45 & 1.45 & 0 & 5.00 \\
Flood i & 91,854 & 2.04 & 1.03 & 0 & 4.06 \\
Agri VA ct & 91,854 & 25.61 & 16.35 & 0.89 & 93.98 \\
FF-Min exp ct & 91,854 & 40.21 & 38.34 & 0.01 & 99.70 \\
Agricult it & 91,854 & 3.36 & 10.57 & 0 & 65.97 \\
Resources it & 91,854 & 9.49 & 25.03 & 0 & 99.70 \\
Inst-PRS ct & 91,854 & 2.75 & 0.89 & 0.30 & 5.40 \\
Inst-Gov-Eff ct & 91,854 & 2.80 & 1.24 & 0 & 6.00 \\
Inst-Law ct & 91,854 & 7.39 & 2.44 & 0 & 11.58 \\
\hline
\end{tabular}




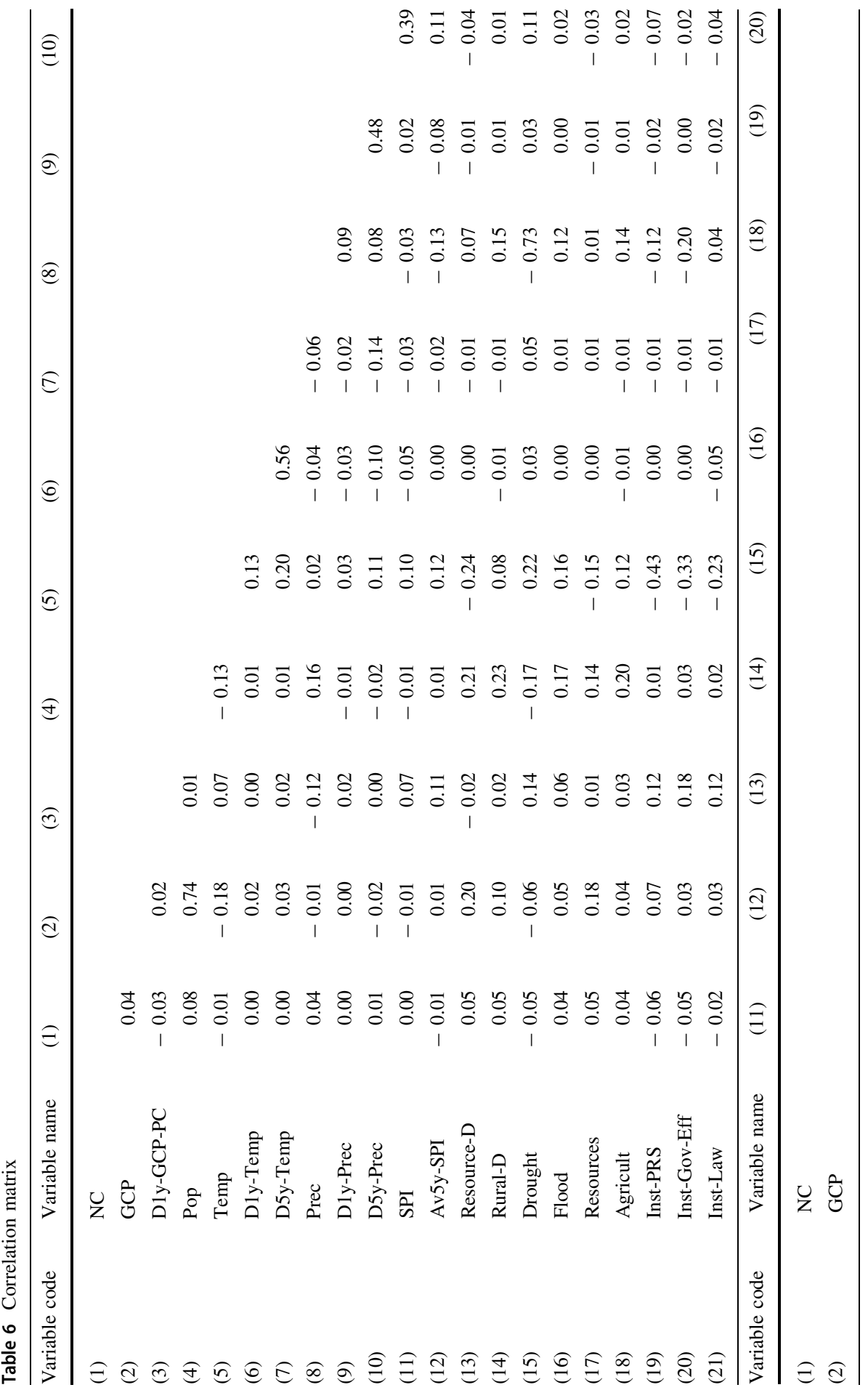




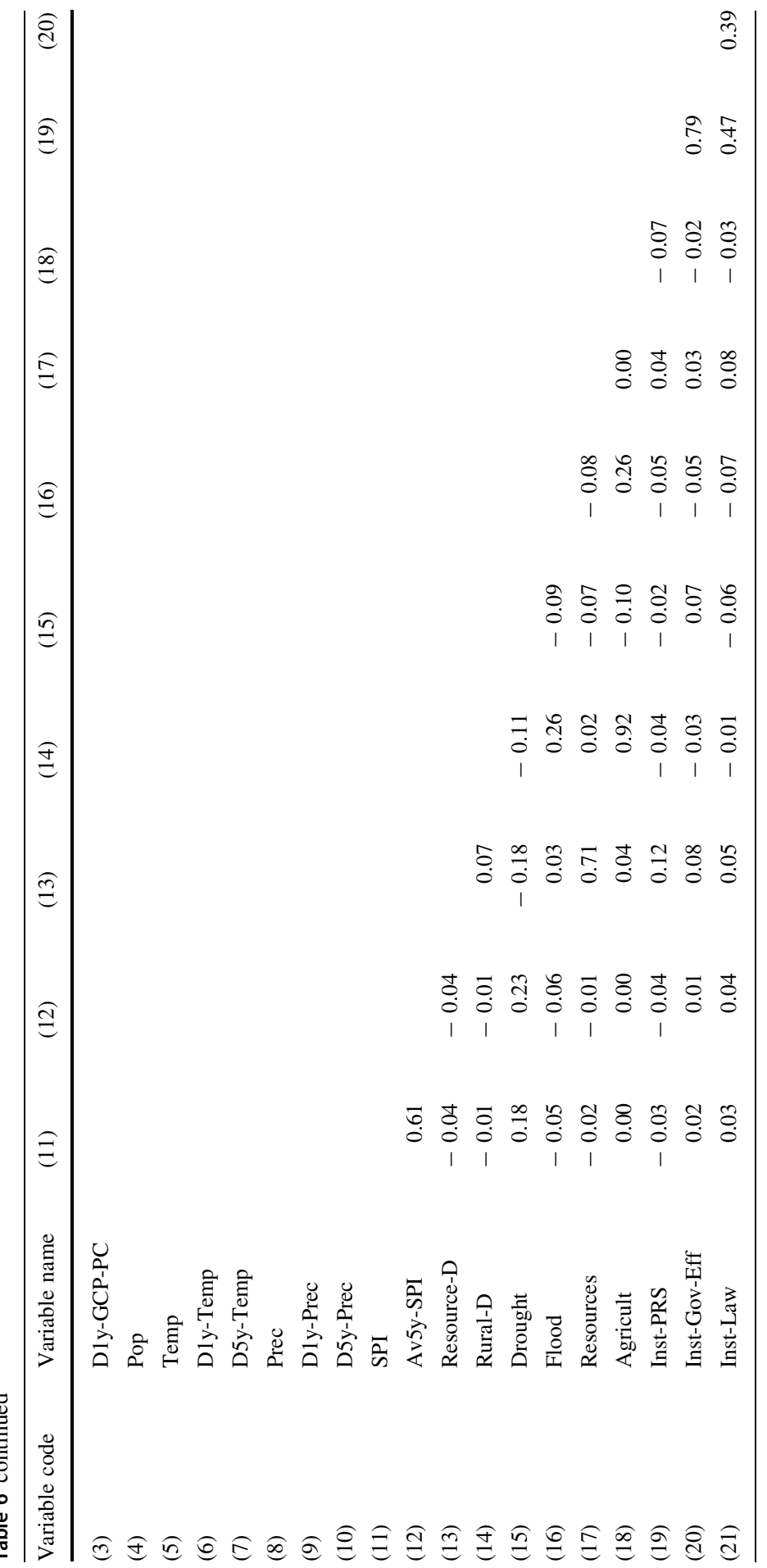


Table 7 Moran's I

\begin{tabular}{|c|c|c|c|c|c|c|c|c|c|c|c|c|}
\hline Year & $\mathrm{NC}$ & GCP & POP & TEMP & PREC & SPI & $\mathrm{NC}$ & GCP & POP & TEMP & PREC & SPI \\
\hline & \multicolumn{6}{|c|}{$150 \mathrm{KM}$} & \multicolumn{6}{|c|}{$250 \mathrm{KM}$} \\
\hline 1990 & 0.13 & 0.19 & 0.29 & 0.75 & 0.98 & 0.72 & 0.09 & 0.17 & 0.25 & 0.76 & 0.94 & 0.64 \\
\hline 1991 & .14 & & 0.30 & 0.74 & & & 0.09 & & & & & 0.64 \\
\hline 1992 & 11 & 0.19 & 0.30 & 0.72 & 0.97 & 0.77 & 0.10 & 0.17 & 0.26 & 0.72 & 0.93 & 0.72 \\
\hline 1993 & 10 & 0.20 & 0.30 & 0.74 & 0.97 & 0.66 & 0.09 & 0.17 & 0.25 & 0.75 & 0.93 & 0.60 \\
\hline 1994 & 15 & 0.20 & 0.30 & 0.74 & 0.98 & 0.70 & 0.10 & 0.17 & 0.26 & 0.74 & 0.94 & 0.61 \\
\hline 1995 & 15 & 0.20 & 0.30 & 0.73 & 0.96 & 0.90 & 0.11 & 0.17 & 0.26 & 0.74 & 0.93 & 0.82 \\
\hline 1996 & 26 & 0.20 & 0.30 & 0.74 & 0.96 & 0.67 & 0.18 & 0.17 & 0.26 & 0.75 & 0.92 & 0.63 \\
\hline 1997 & 21 & 0.20 & 0.30 & 0.74 & 0.94 & 0.76 & 0.15 & 0.17 & 0.26 & 0.76 & 0.92 & 0.67 \\
\hline 1998 & 20 & 0.20 & 0.31 & 0.75 & 0.97 & 0.90 & 0.14 & 0.17 & 0.26 & 0.76 & 0.93 & 0.80 \\
\hline 1999 & 22 & 0.20 & 0.30 & 0.76 & 1.01 & 0.79 & 0.16 & 0.17 & 0.26 & 0.76 & 0.97 & 0.69 \\
\hline 2000 & 0.20 & 0.20 & 0.31 & 0.75 & 0.97 & 0.85 & 0.13 & 0.17 & 0.26 & 0.76 & 0.94 & 0.79 \\
\hline 2001 & .20 & 0.20 & 0.31 & 0.74 & 0.95 & 0.85 & 0.14 & 0.18 & 0.27 & 0.74 & 0.92 & 0.77 \\
\hline 2002 & 33 & 0.20 & 0.31 & 0.73 & 0.95 & 0.83 & 0.15 & 0.18 & 0.26 & 0.75 & & 0.77 \\
\hline 2003 & 19 & 0.20 & 0.31 & 0.74 & 0.97 & 0.80 & 0.13 & 0.18 & 0.27 & 0.75 & 0.93 & 0.72 \\
\hline 2004 & 0.18 & 0.21 & 0.31 & 0.75 & 0.97 & 0.80 & 0.12 & 0.18 & 0.26 & 0.76 & 0.93 & 0.71 \\
\hline 2005 & 16 & 0.21 & 0.31 & 0.72 & 0.94 & 0.78 & 0.10 & 0.19 & 0.27 & & & 0.69 \\
\hline 2006 & 18 & 0.21 & 0.32 & 0.76 & 0.96 & 0.90 & 0.13 & 0.19 & 0.27 & 0.77 & 0.93 & 0.82 \\
\hline 2007 & 0.03 & 0.21 & 0.31 & 0.76 & 0.97 & 0.80 & 0.02 & 0.19 & 0.27 & 0.77 & 0.94 & 0.75 \\
\hline 2008 & 07 & 0.21 & 0.32 & 0.76 & 1.00 & 0.64 & 0.05 & 0.19 & 0.27 & 0.77 & & 0.60 \\
\hline 2009 & & 0.21 & 0.32 & 0.78 & & & & & & & & 0.49 \\
\hline 2010 & 0.02 & 0.21 & 0.32 & 0.78 & 0.94 & 0.56 & 0.02 & 0.19 & 0.27 & 0.79 & 0.90 & 0.48 \\
\hline 2011 & 04 & 0.21 & 0.32 & 0.78 & 0.95 & 0.62 & 0.04 & 0.19 & 0.27 & 0.79 & 0.91 & 0.51 \\
\hline 2012 & & & & & & & & & & & & 0.54 \\
\hline 2013 & .15 & 0.21 & 0.32 & 0.83 & 0.94 & 0.68 & 0.11 & 0.19 & 0.27 & 0.82 & 0.91 & 0.59 \\
\hline 2014 & 19 & 0.21 & 0.32 & 0.77 & 1.01 & 0.64 & 0.14 & 0.19 & 0.27 & 0.78 & 0.95 & 0.56 \\
\hline 2015 & & 0.21 & & & & & & & & & & 0.67 \\
\hline 2016 & & 0.21 & 0.32 & & & & 0.14 & & 0.27 & & 0.98 & 0.73 \\
\hline \multirow[t]{2}{*}{ Average } & 0.16 & 0.20 & 0.31 & 0.75 & 0.97 & 0.74 & 0.11 & 0.18 & 0.26 & 0.76 & 0.93 & 0.67 \\
\hline & \multicolumn{6}{|c|}{$500 \mathrm{KM}$} & \multicolumn{6}{|c|}{$1000 \mathrm{KM}$} \\
\hline 1990 & 0.05 & 0.13 & 0.19 & 0.70 & & 0.52 & 0.03 & 0.07 & & & & 0.35 \\
\hline 1991 & 0.06 & 0.13 & 0.19 & 0.70 & 0.87 & 0.52 & 0.04 & 0.07 & 0.12 & 0.58 & 0.76 & 0.35 \\
\hline 1992 & 0.06 & 0.12 & 0.20 & 0.66 & 0.87 & 0.61 & 0.04 & 0.07 & 0.12 & 0.54 & 0.76 & 0.46 \\
\hline 1993 & 0.06 & 0.13 & 0.19 & 0.69 & 0.87 & 0.48 & 0.03 & 0.07 & 0.12 & 0.57 & 0.74 & 0.31 \\
\hline 1994 & 0.06 & 0.12 & 0.20 & 0.68 & 0.88 & 0.48 & 0.03 & 0.07 & 0.12 & 0.55 & 0.76 & 0.31 \\
\hline 1995 & 0.07 & 0.12 & 0.20 & 0.67 & 0.87 & 0.72 & 0.04 & 0.07 & 0.12 & 0.55 & 0.74 & 0.57 \\
\hline 1996 & & 0.12 & 0.19 & 0.70 & 0.85 & 0.52 & 0.06 & 0.07 & 0.12 & 0.58 & 0.72 & 0.38 \\
\hline 1997 & 0.10 & 0.12 & 0.20 & 0.70 & 0.87 & 0.54 & 0.05 & 0.07 & 0.12 & 0.58 & 0.77 & 0.36 \\
\hline 1998 & 0.09 & 0.12 & 0.20 & 0.70 & 0.88 & 0.69 & 0.05 & 0.07 & 0.12 & 0.58 & 0.76 & 0.52 \\
\hline 1999 & 0.10 & 0.12 & 0.20 & 0.69 & 0.91 & 0.54 & 0.06 & 0.07 & 0.12 & 0.57 & 0.78 & 0.33 \\
\hline 2000 & 0.09 & 0.12 & 0.20 & 0.70 & 0.88 & 0.63 & 0.05 & 0.07 & 0.12 & 0.58 & 0.75 & 0.42 \\
\hline 2001 & 0.10 & 0.13 & 0.20 & 0.68 & 0.87 & 0.63 & 0.05 & 0.07 & 0.12 & 0.56 & 0.76 & 0.41 \\
\hline
\end{tabular}


Table 7 continued

\begin{tabular}{lllllllllllll}
\hline Year & NC & GCP & POP & TEMP & PREC & SPI & NC & GCP & POP & TEMP & PREC & SPI \\
\hline 2002 & 0.09 & 0.13 & 0.20 & 0.69 & 0.86 & 0.62 & 0.06 & 0.07 & 0.12 & 0.57 & 0.75 & 0.39 \\
2003 & 0.08 & 0.13 & 0.20 & 0.69 & 0.87 & 0.57 & 0.05 & 0.08 & 0.12 & 0.57 & 0.75 & 0.34 \\
2004 & 0.08 & 0.13 & 0.20 & 0.70 & 0.87 & 0.57 & 0.04 & 0.08 & 0.12 & 0.58 & 0.75 & 0.36 \\
2005 & 0.06 & 0.13 & 0.20 & 0.67 & 0.87 & 0.55 & 0.04 & 0.08 & 0.12 & 0.55 & 0.77 & 0.35 \\
2006 & 0.09 & 0.14 & 0.21 & 0.71 & 0.87 & 0.68 & 0.06 & 0.08 & 0.13 & 0.60 & 0.77 & 0.43 \\
2007 & 0.02 & 0.14 & 0.20 & 0.71 & 0.88 & 0.64 & 0.01 & 0.08 & 0.13 & 0.59 & 0.77 & 0.48 \\
2008 & 0.03 & 0.14 & 0.21 & 0.71 & 0.90 & 0.48 & 0.02 & 0.08 & 0.13 & 0.59 & 0.77 & 0.33 \\
2009 & 0.06 & 0.14 & 0.21 & 0.73 & 0.89 & 0.36 & 0.04 & 0.08 & 0.13 & 0.62 & 0.78 & 0.23 \\
2010 & 0.02 & 0.14 & 0.21 & 0.73 & 0.85 & 0.35 & 0.01 & 0.08 & 0.13 & 0.62 & 0.73 & 0.20 \\
2011 & 0.03 & 0.14 & 0.21 & 0.73 & 0.85 & 0.39 & 0.02 & 0.08 & 0.13 & 0.61 & 0.75 & 0.25 \\
2012 & 0.07 & 0.14 & 0.21 & 0.72 & 0.84 & 0.43 & 0.04 & 0.08 & 0.13 & 0.60 & 0.72 & 0.30 \\
2013 & 0.08 & 0.14 & 0.21 & 0.76 & 0.85 & 0.49 & 0.04 & 0.08 & 0.13 & 0.64 & 0.74 & 0.39 \\
2014 & 0.10 & 0.14 & 0.21 & 0.72 & 0.89 & 0.43 & 0.06 & 0.08 & 0.13 & 0.60 & 0.75 & 0.27 \\
2015 & 0.12 & 0.14 & 0.21 & 0.66 & 0.90 & 0.57 & 0.06 & 0.08 & 0.13 & 0.52 & 0.76 & 0.45 \\
2016 & 0.09 & 0.15 & 0.21 & 0.67 & 0.91 & 0.63 & 0.05 & 0.08 & 0.13 & 0.54 & 0.77 & 0.49 \\
Average & 0.07 & 0.13 & 0.20 & 0.70 & 0.87 & 0.54 & 0.04 & 0.08 & 0.12 & 0.58 & 0.76 & 0.37 \\
\hline
\end{tabular}

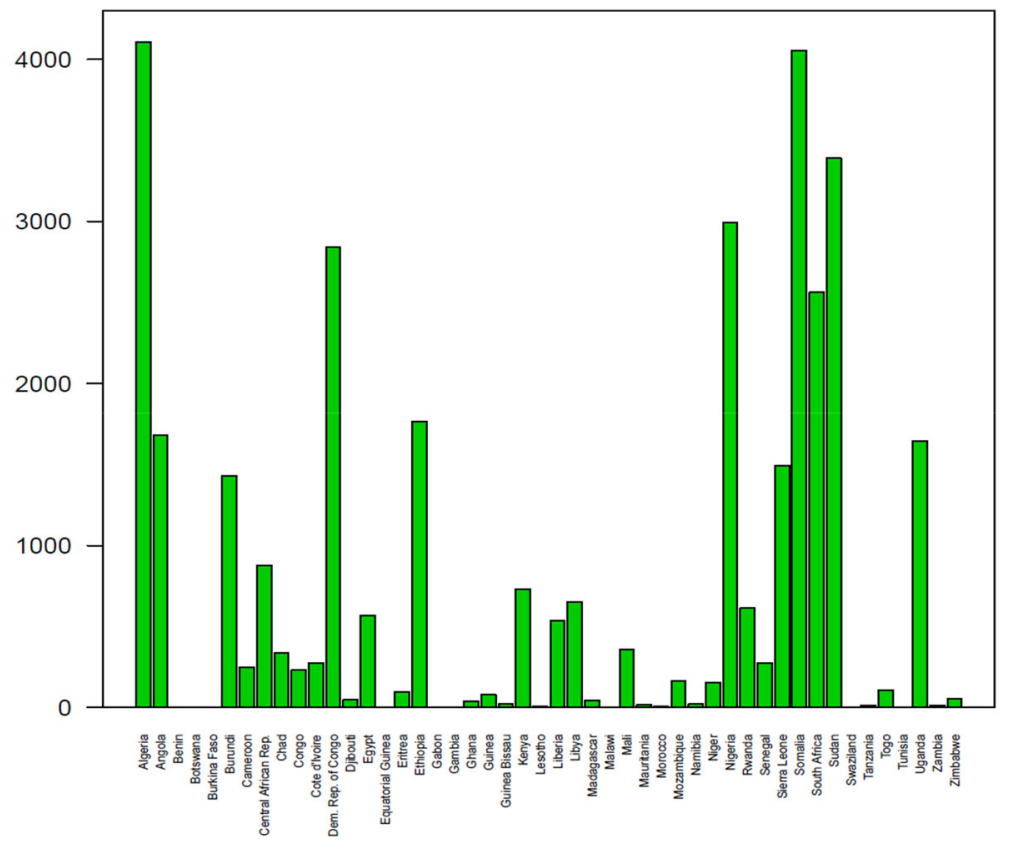

Fig. 3 Total number of conflicting events by country (1990-2016) 


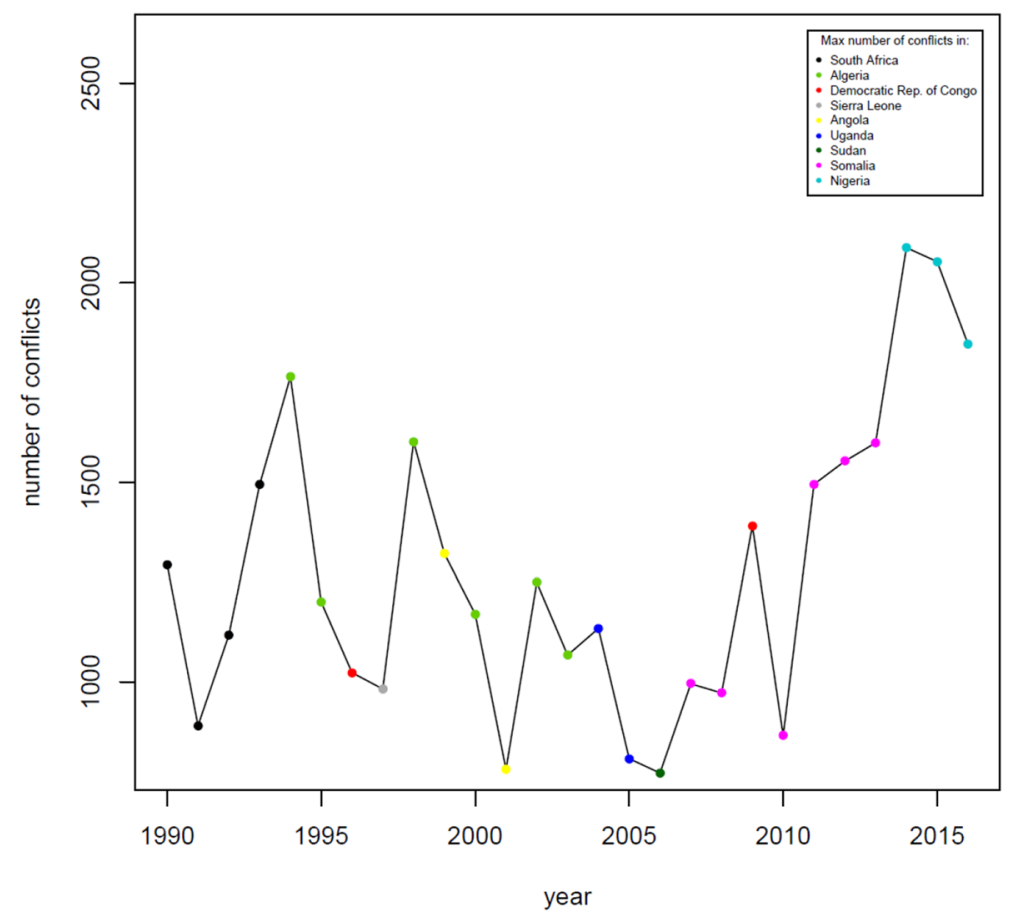

Fig. 4 Total number of conflicting events by year (peak countries highlighted) 
Max distance great circle formula
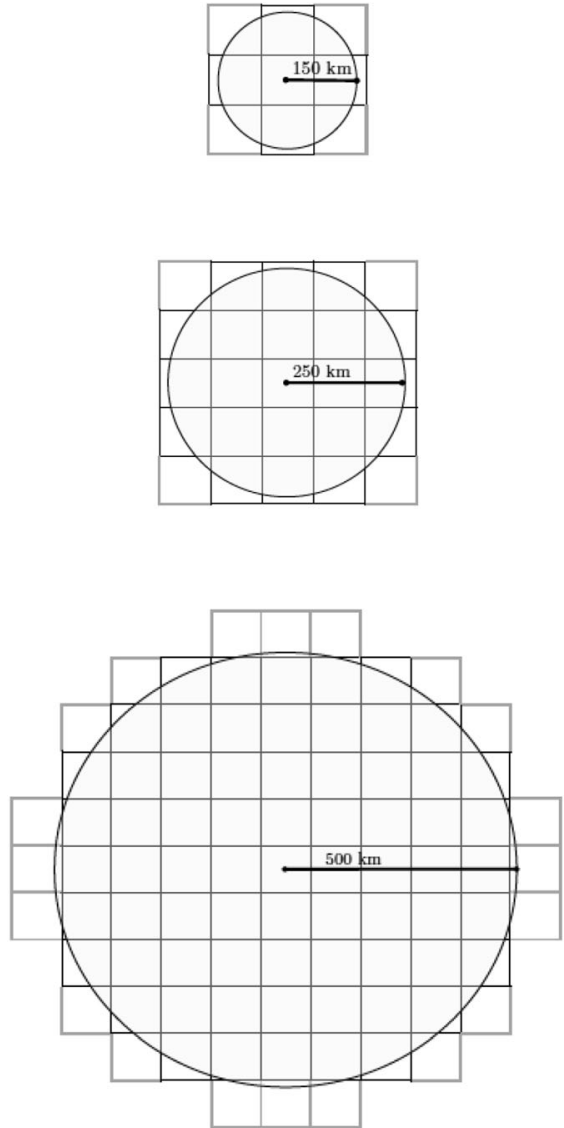

Max distance great circle formula+Queen
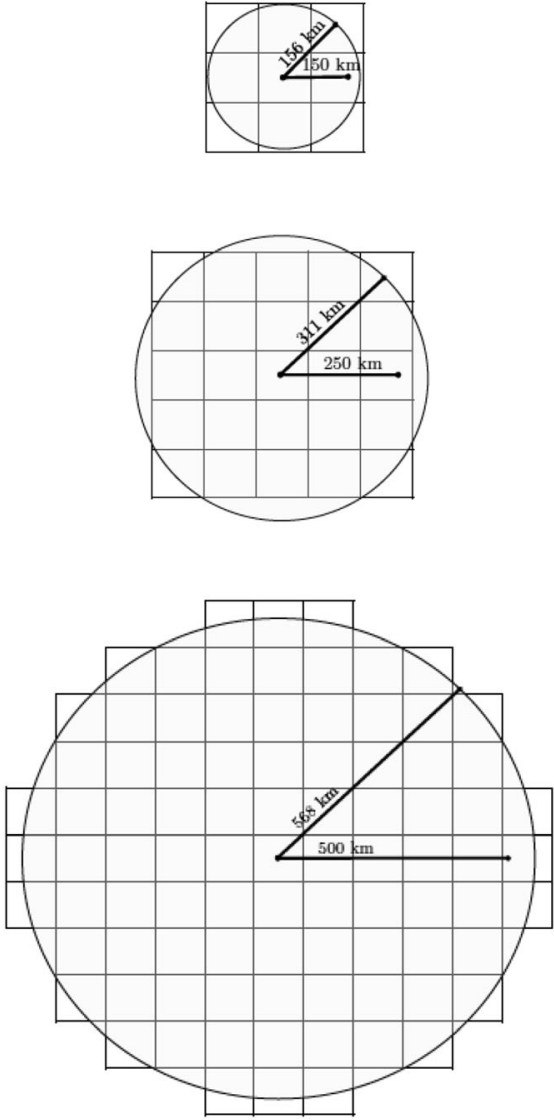

Fig. 5 Cut-off distances with great circle formula and Queen approach 

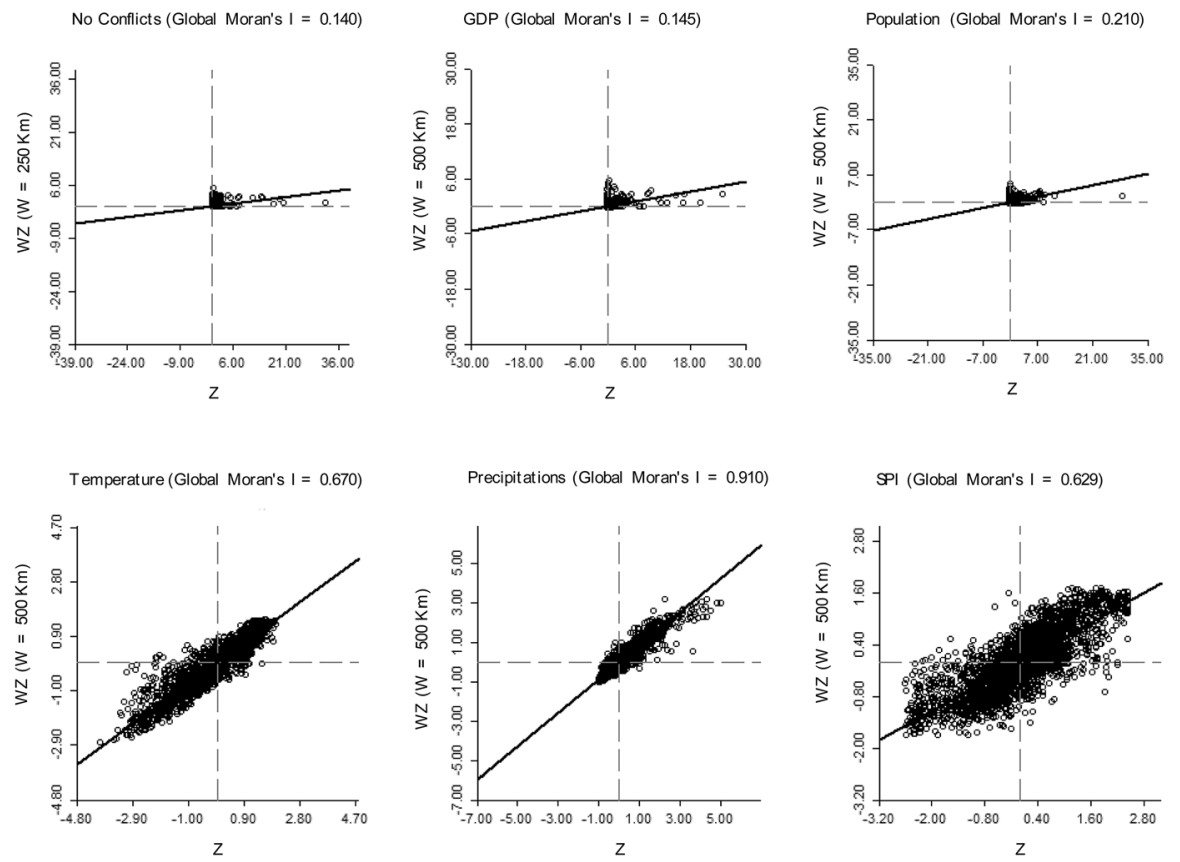

Fig. 6 Moran's scatterplot for main variables (calculated for year 2016)

\section{Appendix 2}

See Tables 8, 9, 10 and 11. 
Table 8 Parameters for different weight matrixes in SDM and model choice

\begin{tabular}{|c|c|c|c|c|c|c|}
\hline & $\begin{array}{l}\text { (W150- } \\
\text { D150) }\end{array}$ & $\begin{array}{l}\text { (W150- } \\
\text { D250) }\end{array}$ & $\begin{array}{l}\text { (W150- } \\
\text { D500) }\end{array}$ & $\begin{array}{l}\text { (W250- } \\
\text { D150) }\end{array}$ & $\begin{array}{l}\text { (W250- } \\
\text { D250) }\end{array}$ & $\begin{array}{l}\text { (W250- } \\
\text { D500) }\end{array}$ \\
\hline $\mathrm{NC}$ it-1 $(\alpha)$ & $\begin{array}{l}0.475^{* * *} \\
(0.01)\end{array}$ & $\begin{array}{l}0.534 * * * \\
(0.01)\end{array}$ & $\begin{array}{l}0.479 * * * \\
(0.01)\end{array}$ & $\begin{array}{l}0.480 * * * \\
(0.01)\end{array}$ & $\begin{array}{l}0.479 * * * \\
(0.01)\end{array}$ & $\begin{array}{l}0.473 * * * \\
(0.01)\end{array}$ \\
\hline $\begin{array}{l}\mathrm{W}_{150 / 250} \mathrm{NC} \text { it } \\
(\rho)\end{array}$ & $\begin{array}{l}0.661 * * * \\
(0.02)\end{array}$ & $\begin{array}{l}1.189^{* * * *} \\
(0.02)\end{array}$ & $\begin{array}{l}0.718^{* * * *} \\
(0.02)\end{array}$ & $\begin{array}{l}0.576^{* * * *} \\
(0.01)\end{array}$ & $\begin{array}{l}0.558 * * * \\
(0.01)\end{array}$ & $\begin{array}{l}0.527 * * * \\
(0.01)\end{array}$ \\
\hline GCP it-1 & $\begin{array}{l}-0.017 * * \\
(0.01)\end{array}$ & $\begin{array}{l}-0.001 \\
(0.01)\end{array}$ & $\begin{array}{l}-0.024 * * * \\
(0.01)\end{array}$ & $\begin{array}{l}-0.011 \\
(0.01)\end{array}$ & $\begin{array}{l}-0.021 * * \\
(0.01)\end{array}$ & $\begin{array}{l}-0.023 * * * \\
(0.01)\end{array}$ \\
\hline Pop it-1 & $\begin{array}{l}0.037 * * \\
(0.02)\end{array}$ & $\begin{array}{l}0.022 \\
(0.02)\end{array}$ & $\begin{array}{l}0.046^{* * * *} \\
(0.01)\end{array}$ & $\begin{array}{l}0.033 * * \\
(0.02)\end{array}$ & $\begin{array}{l}0.037 * * \\
(0.02)\end{array}$ & $\begin{array}{l}0.046^{* * * *} \\
(0.02)\end{array}$ \\
\hline Temp it-1 & $\begin{array}{l}-0.138 * \\
(0.08)\end{array}$ & $\begin{array}{l}0.706^{* * * *} \\
(0.09)\end{array}$ & $\begin{array}{l}0.913 * * * \\
(0.08)\end{array}$ & $\begin{array}{l}-0.106 \\
(0.08)\end{array}$ & $\begin{array}{l}0.521 * * * \\
(0.09)\end{array}$ & $\begin{array}{l}0.825^{* * *} \\
(0.08)\end{array}$ \\
\hline Prec it-1 & $\begin{array}{l}-0.003 \\
(0.01)\end{array}$ & $\begin{array}{l}0.019 * * * \\
(0.01)\end{array}$ & $\begin{array}{l}0.011 * * \\
(0.01)\end{array}$ & $\begin{array}{l}0.003 \\
(0.01)\end{array}$ & $\begin{array}{l}0.011^{*} \\
(0.01)\end{array}$ & $\begin{array}{l}0.015^{* * * *} \\
(0.01)\end{array}$ \\
\hline SPI it-1 & $\begin{array}{l}-0.022^{* *} \\
(0.01)\end{array}$ & $\begin{array}{l}-0.023^{* *} \\
(0.01)\end{array}$ & $\begin{array}{l}-0.016^{*} \\
(0.01)\end{array}$ & $\begin{array}{l}-0.022^{* *} \\
(0.01)\end{array}$ & $\begin{array}{l}-0.022 * * \\
(0.01)\end{array}$ & $\begin{array}{l}-0.018^{* *} \\
(0.01)\end{array}$ \\
\hline Resources it & $\begin{array}{l}-0.000 \\
(0.00)\end{array}$ & $\begin{array}{l}0.000 \\
(0.00)\end{array}$ & $\begin{array}{l}-0.000 \\
(0.00)\end{array}$ & $\begin{array}{l}-0.000 \\
(0.00)\end{array}$ & $\begin{array}{l}-0.000 \\
(0.00)\end{array}$ & $\begin{array}{l}-0.000 \\
(0.00)\end{array}$ \\
\hline Agricult it & $\begin{array}{l}-0.002 * * \\
(0.00)\end{array}$ & $\begin{array}{l}-0.001 \\
(0.00)\end{array}$ & $\begin{array}{l}-0.002 * * \\
(0.00)\end{array}$ & $\begin{array}{l}-0.001 \\
(0.00)\end{array}$ & $\begin{array}{l}-0.001 \\
(0.00)\end{array}$ & $\begin{array}{l}-0.002 * \\
(0.00)\end{array}$ \\
\hline $\begin{array}{l}\mathrm{Nr} \text { year from } \\
\text { indep ct }\end{array}$ & $\begin{array}{l}0.077 * * * \\
(0.01)\end{array}$ & $\begin{array}{l}0.151 * * * \\
(0.01)\end{array}$ & $\begin{array}{l}0.085 * * * \\
(0.01)\end{array}$ & $\begin{array}{l}0.096 * * * \\
(0.01)\end{array}$ & $\begin{array}{l}0.092 * * * \\
(0.01)\end{array}$ & $\begin{array}{l}0.085^{* * * *} \\
(0.01)\end{array}$ \\
\hline Inst-PRS ct & $\begin{array}{l}-0.014 * * * \\
(0.00)\end{array}$ & $\begin{array}{l}-0.004 \\
(0.00)\end{array}$ & $\begin{array}{l}-0.013 * * * \\
(0.00)\end{array}$ & $\begin{array}{l}-0.012^{* * * *} \\
(0.00)\end{array}$ & $\begin{array}{l}-0.012 * * * \\
(0.00)\end{array}$ & $\begin{array}{l}-0.013^{* * *} \\
(0.00)\end{array}$ \\
\hline \multicolumn{7}{|c|}{ Spatial spillovers with $D_{150 / 250 / 500}$ inverse distance weight matrix } \\
\hline GCP it-1 & $\begin{array}{l}-0.000 \\
(0.01)\end{array}$ & $\begin{array}{l}-0.012 \\
(0.01)\end{array}$ & $\begin{array}{l}0.008 \\
(0.01)\end{array}$ & $\begin{array}{l}-0.015 \\
(0.02)\end{array}$ & $\begin{array}{l}0.008 \\
(0.01)\end{array}$ & $\begin{array}{l}0.007 \\
(0.01)\end{array}$ \\
\hline Pop it-1 & $\begin{array}{l}0.006 \\
(0.03)\end{array}$ & $\begin{array}{l}0.059 * * * \\
(0.02)\end{array}$ & $\begin{array}{l}0.003 \\
(0.01)\end{array}$ & $\begin{array}{l}0.017 \\
(0.03)\end{array}$ & $\begin{array}{l}0.008 \\
(0.02)\end{array}$ & $\begin{array}{l}-0.002 \\
(0.01)\end{array}$ \\
\hline Temp it-1 & $\begin{array}{l}1.045^{* * * *} \\
(0.11)\end{array}$ & $\begin{array}{l}-0.418 * * * \\
(0.07)\end{array}$ & $\begin{array}{l}-0.285^{* * *} \\
(0.04)\end{array}$ & $\begin{array}{l}0.649 * * * \\
(0.11)\end{array}$ & $\begin{array}{l}-0.236 * * * \\
(0.07)\end{array}$ & $\begin{array}{l}-0.317 * * * \\
(0.04)\end{array}$ \\
\hline Prec it-1 & $\begin{array}{l}0.016^{*} \\
(0.01)\end{array}$ & $\begin{array}{l}-0.026^{* * *} \\
(0.01)\end{array}$ & $\begin{array}{l}-0.006^{* *} \\
(0.00)\end{array}$ & $\begin{array}{l}-0.007 \\
(0.01)\end{array}$ & $\begin{array}{l}-0.014^{* *} \\
(0.01)\end{array}$ & $\begin{array}{l}-0.011 * * * \\
(0.00)\end{array}$ \\
\hline SPI it-1 & $\begin{array}{l}0.037 * * * \\
(0.01)\end{array}$ & $\begin{array}{l}0.024 * * * \\
(0.01)\end{array}$ & $\begin{array}{l}0.010 * * \\
(0.00)\end{array}$ & $\begin{array}{l}0.036 * * * \\
(0.01)\end{array}$ & $\begin{array}{l}0.021 * * \\
(0.01)\end{array}$ & $\begin{array}{l}0.011 * * \\
(0.00)\end{array}$ \\
\hline $\begin{array}{r}\text { Variance } \\
\text { sigma2 }\end{array}$ & $0.069 * * *$ & $0.066^{* * *}$ & $0.069 * * *$ & $0.069 * * *$ & $0.069 * * *$ & $0.069 * * *$ \\
\hline Nr Obs. & 88,452 & 88,452 & 88,452 & 88,452 & 88,452 & 88,452 \\
\hline R2_within & 0.164 & 0.001 & 0.149 & 0.001 & 0.026 & 0.057 \\
\hline R2_between & 0.000 & 0.015 & 0.040 & 0.002 & 0.006 & 0.024 \\
\hline R2_overall & 0.000 & 0.000 & 0.000 & 0.000 & 0.000 & 0.000 \\
\hline Log-likelihood & -7274 & -7270 & -7266 & -7186 & -7182 & -7179 \\
\hline AIC & 14,581 & 14,573 & 14,566 & 14,406 & 14,397 & 14,393 \\
\hline
\end{tabular}


Table 8 continued

\begin{tabular}{|c|c|c|c|c|c|c|}
\hline & $\begin{array}{l}\text { (W150- } \\
\text { D150) }\end{array}$ & $\begin{array}{l}\text { (W150- } \\
\text { D250) }\end{array}$ & $\begin{array}{l}\text { (W150- } \\
\text { D500) }\end{array}$ & $\begin{array}{l}\text { (W250- } \\
\text { D150) }\end{array}$ & $\begin{array}{l}\text { (W250- } \\
\text { D250) }\end{array}$ & $\begin{array}{l}\text { (W250- } \\
\text { D500) }\end{array}$ \\
\hline BIC & 14,741 & 14,733 & 14,726 & 14,566 & 14,557 & 14,552 \\
\hline $\begin{array}{l}\text { LR test wrt } \\
\text { SAR }\end{array}$ & & & & & & $32.78 * * *$ \\
\hline $\begin{array}{l}\text { LR test wrt } \\
\text { SLX }\end{array}$ & & & & & & $11,214.64 * * *$ \\
\hline
\end{tabular}

Robust (clustered id) standard errors in parentheses; $* p<0.1, * * p<0.05, * * * p<0.01$

Table 9 Parameters for climate and socio-economic conditions ( $\left.\mathrm{SDM}_{250-500}\right)$

\begin{tabular}{|c|c|c|c|c|c|c|}
\hline & (1) & (2) & (3) & (4) & (5) & (6) \\
\hline NC it-1 $(\alpha)$ & $\begin{array}{l}0.473 * * * \\
(0.01)\end{array}$ & $\begin{array}{l}0.485^{* * * *} \\
(0.01)\end{array}$ & $\begin{array}{l}0.481 * * * \\
(0.01)\end{array}$ & $\begin{array}{l}0.476^{* * * *} \\
(0.01)\end{array}$ & $\begin{array}{l}0.522 * * * \\
(0.01)\end{array}$ & $\begin{array}{l}0.471 * * * \\
(0.01)\end{array}$ \\
\hline $\mathrm{W}_{250} \mathrm{NC}$ it $(\rho)$ & $\begin{array}{l}0.525 * * * \\
(0.01)\end{array}$ & $\begin{array}{l}0.619 * * * \\
(0.01)\end{array}$ & $\begin{array}{l}0.597 * * * \\
(0.01)\end{array}$ & $\begin{array}{l}0.560 * * * \\
(0.01)\end{array}$ & $\begin{array}{l}0.843 * * * \\
(0.01)\end{array}$ & $\begin{array}{l}0.512 * * * \\
(0.01)\end{array}$ \\
\hline GCP it-1 & $\begin{array}{l}-0.028 * * * \\
(0.01)\end{array}$ & $\begin{array}{l}-0.020^{* *} \\
(0.01)\end{array}$ & $\begin{array}{l}-0.020 * * \\
(0.01)\end{array}$ & $\begin{array}{l}-0.025^{* *} \\
(0.01)\end{array}$ & $\begin{array}{l}0.004 \\
(0.01)\end{array}$ & $\begin{array}{l}-0.027 * * * \\
(0.01)\end{array}$ \\
\hline Pop it-1 & $\begin{array}{l}0.060 * * * \\
(0.02)\end{array}$ & $\begin{array}{l}0.055^{* * * *} \\
(0.02)\end{array}$ & $\begin{array}{l}0.056 * * * \\
(0.02)\end{array}$ & $\begin{array}{l}0.056 * * * \\
(0.02)\end{array}$ & $\begin{array}{l}0.041^{* *} \\
(0.02)\end{array}$ & $\begin{array}{l}0.062 * * * \\
(0.02)\end{array}$ \\
\hline Temp it-1 & $\begin{array}{l}0.814 * * * \\
(0.08)\end{array}$ & $\begin{array}{l}0.855^{* * * *} \\
(0.08)\end{array}$ & $\begin{array}{l}0.846^{* * * *} \\
(0.08)\end{array}$ & $\begin{array}{l}0.831 * * * \\
(0.08)\end{array}$ & $\begin{array}{l}0.970 * * * \\
(0.08)\end{array}$ & $\begin{array}{l}0.803 * * * \\
(0.08)\end{array}$ \\
\hline Prec it-1 & $\begin{array}{l}0.017 * * * \\
(0.01)\end{array}$ & $\begin{array}{l}0.021 * * * \\
(0.01)\end{array}$ & $\begin{array}{l}0.020 * * * \\
(0.01)\end{array}$ & $\begin{array}{l}0.018^{* * * *} \\
(0.01)\end{array}$ & $\begin{array}{l}0.031 * * * \\
(0.01)\end{array}$ & $\begin{array}{l}0.016 * * * \\
(0.01)\end{array}$ \\
\hline SPI it-1 & $\begin{array}{l}-0.022^{* *} \\
(0.01)\end{array}$ & $\begin{array}{l}-0.023^{* *} \\
(0.01)\end{array}$ & $\begin{array}{l}-0.022 * * \\
(0.01)\end{array}$ & $\begin{array}{l}-0.022 * * \\
(0.01)\end{array}$ & $\begin{array}{l}-0.024 * * * \\
(0.01)\end{array}$ & $\begin{array}{l}-0.021 * * \\
(0.01)\end{array}$ \\
\hline Resources it & $\begin{array}{l}-0.000 \\
(0.00)\end{array}$ & $\begin{array}{l}-0.000 \\
(0.00)\end{array}$ & $\begin{array}{l}-0.000 \\
(0.00)\end{array}$ & $\begin{array}{l}0.002 * * * \\
(0.00)\end{array}$ & $\begin{array}{l}0.000 \\
(0.00)\end{array}$ & $\begin{array}{l}0.002 * * * \\
(0.00)\end{array}$ \\
\hline Int-Resources it & & & & $\begin{array}{l}-0.001 * * \\
(0.00)\end{array}$ & $\begin{array}{l}-0.000 \\
(0.00)\end{array}$ & $\begin{array}{l}-0.001 * * \\
(0.00)\end{array}$ \\
\hline Agricult it & $\begin{array}{l}-0.002 * \\
(0.00)\end{array}$ & $\begin{array}{l}-0.001 \\
(0.00)\end{array}$ & $\begin{array}{l}-0.001 \\
(0.00)\end{array}$ & $\begin{array}{l}-0.001 \\
(0.00)\end{array}$ & $\begin{array}{l}-0.001 \\
(0.00)\end{array}$ & $\begin{array}{l}-0.002 * \\
(0.00)\end{array}$ \\
\hline $\begin{array}{l}\mathrm{Nr} \text { year from } \\
\text { indep ct }\end{array}$ & $\begin{array}{l}0.091 * * * \\
(0.01)\end{array}$ & $\begin{array}{l}0.119 * * * \\
(0.01)\end{array}$ & $\begin{array}{l}0.110 * * * \\
(0.02)\end{array}$ & $\begin{array}{l}0.114 * * * \\
(0.01)\end{array}$ & $\begin{array}{l}0.182 * * * \\
(0.01)\end{array}$ & $\begin{array}{l}0.096 * * * \\
(0.01)\end{array}$ \\
\hline $\begin{array}{c}\text { Inst-Law \& } \\
\text { Order ct }\end{array}$ & $\begin{array}{l}-0.011^{* * *} \\
(0.00)\end{array}$ & & & $\begin{array}{l}-0.010 * * * \\
(0.00)\end{array}$ & & \\
\hline Inst-Gov Eff ct & & $\begin{array}{l}-0.004 * * * \\
(0.00)\end{array}$ & & & $\begin{array}{l}-0.003 * * * \\
(0.00)\end{array}$ & \\
\hline
\end{tabular}


Table 9 continued

\begin{tabular}{|c|c|c|c|c|c|c|}
\hline & (1) & (2) & (3) & (4) & (5) & (6) \\
\hline Inst-PRS ct & & & $\begin{array}{l}-0.014^{* * * *} \\
(0.00)\end{array}$ & & & $\begin{array}{l}-0.012 * * * \\
(0.00)\end{array}$ \\
\hline \multicolumn{7}{|c|}{ Spatial spillovers with $D_{500}$ inverse distance weight matrix } \\
\hline GCP it-1 & $\begin{array}{l}0.005 \\
(0.01)\end{array}$ & $\begin{array}{l}-0.004 \\
(0.01)\end{array}$ & $\begin{array}{l}-0.001 \\
(0.01)\end{array}$ & $\begin{array}{l}-0.000 \\
(0.01)\end{array}$ & $\begin{array}{l}-0.023^{* * *} \\
(0.01)\end{array}$ & $\begin{array}{l}0.004 \\
(0.01)\end{array}$ \\
\hline Pop it-1 & $\begin{array}{l}0.002 \\
(0.01)\end{array}$ & $\begin{array}{l}0.014 \\
(0.01)\end{array}$ & $\begin{array}{l}0.008 \\
(0.01)\end{array}$ & $\begin{array}{l}0.009 \\
(0.01)\end{array}$ & $\begin{array}{l}0.039 * * * \\
(0.01)\end{array}$ & $\begin{array}{l}-0.002 \\
(0.01)\end{array}$ \\
\hline Temp it-1 & $\begin{array}{l}-0.312^{* * * *} \\
(0.04)\end{array}$ & $\begin{array}{l}-0.370^{* * *} \\
(0.04)\end{array}$ & $\begin{array}{l}-0.354 * * * \\
(0.04)\end{array}$ & $\begin{array}{l}-0.335^{* * *} \\
(0.04)\end{array}$ & $\begin{array}{l}-0.514 * * * \\
(0.04)\end{array}$ & $\begin{array}{l}-0.302 * * * \\
(0.04)\end{array}$ \\
\hline Prec it-1 & $\begin{array}{l}-0.012 * * * \\
(0.00)\end{array}$ & $\begin{array}{l}-0.018 * * * \\
(0.00)\end{array}$ & $\begin{array}{l}-0.016^{* * * *} \\
(0.00)\end{array}$ & $\begin{array}{l}-0.014 * * * \\
(0.00)\end{array}$ & $\begin{array}{l}-0.029 * * * \\
(0.00)\end{array}$ & $\begin{array}{l}-0.012 * * * \\
(0.00)\end{array}$ \\
\hline SPI it-1 & $\begin{array}{l}0.012 * * \\
(0.00)\end{array}$ & $\begin{array}{l}0.014 * * * \\
(0.00)\end{array}$ & $\begin{array}{l}0.013 * * * \\
(0.00)\end{array}$ & $\begin{array}{l}0.013 * * * \\
(0.00)\end{array}$ & $\begin{array}{l}0.017 * * * \\
(0.00)\end{array}$ & $\begin{array}{l}0.012 * * \\
(0.00)\end{array}$ \\
\hline Variance sigma2 & $0.070 * * *$ & $0.069 * * *$ & $0.069 * * *$ & $0.069 * * *$ & $0.067 * * *$ & $0.070 * * *$ \\
\hline $\mathrm{Nr}$ Obs. & 88,452 & 88,452 & 88,452 & 88,452 & 88,452 & 88,452 \\
\hline R2_within & 0.046 & 0.008 & 0.001 & 0.041 & 0.001 & 0.018 \\
\hline R2_between & 0.063 & 0.000 & 0.005 & 0.008 & 0.001 & 0.025 \\
\hline R2_overall & 0.000 & 0.000 & 0.000 & 0.000 & 0.000 & 0.000 \\
\hline Log-likelihood & -6835 & -6859 & -6834 & -6815 & -6851 & -6776 \\
\hline AIC & 13,705 & 13,751 & 13,703 & 13,667 & 13,738 & 13,588 \\
\hline $\mathrm{BIC}$ & 13,863 & 13,909 & 13,861 & 13,834 & 13,906 & 13,755 \\
\hline $\begin{array}{c}\text { Condition } \\
\text { number }\end{array}$ & 26.13 & 26.04 & 26.07 & 26.21 & 26.07 & 26.15 \\
\hline
\end{tabular}

Robust (clustered id) standard errors in parentheses; ${ }^{*} p<0.1, * * p<0.05, * * * p<0.01$ 


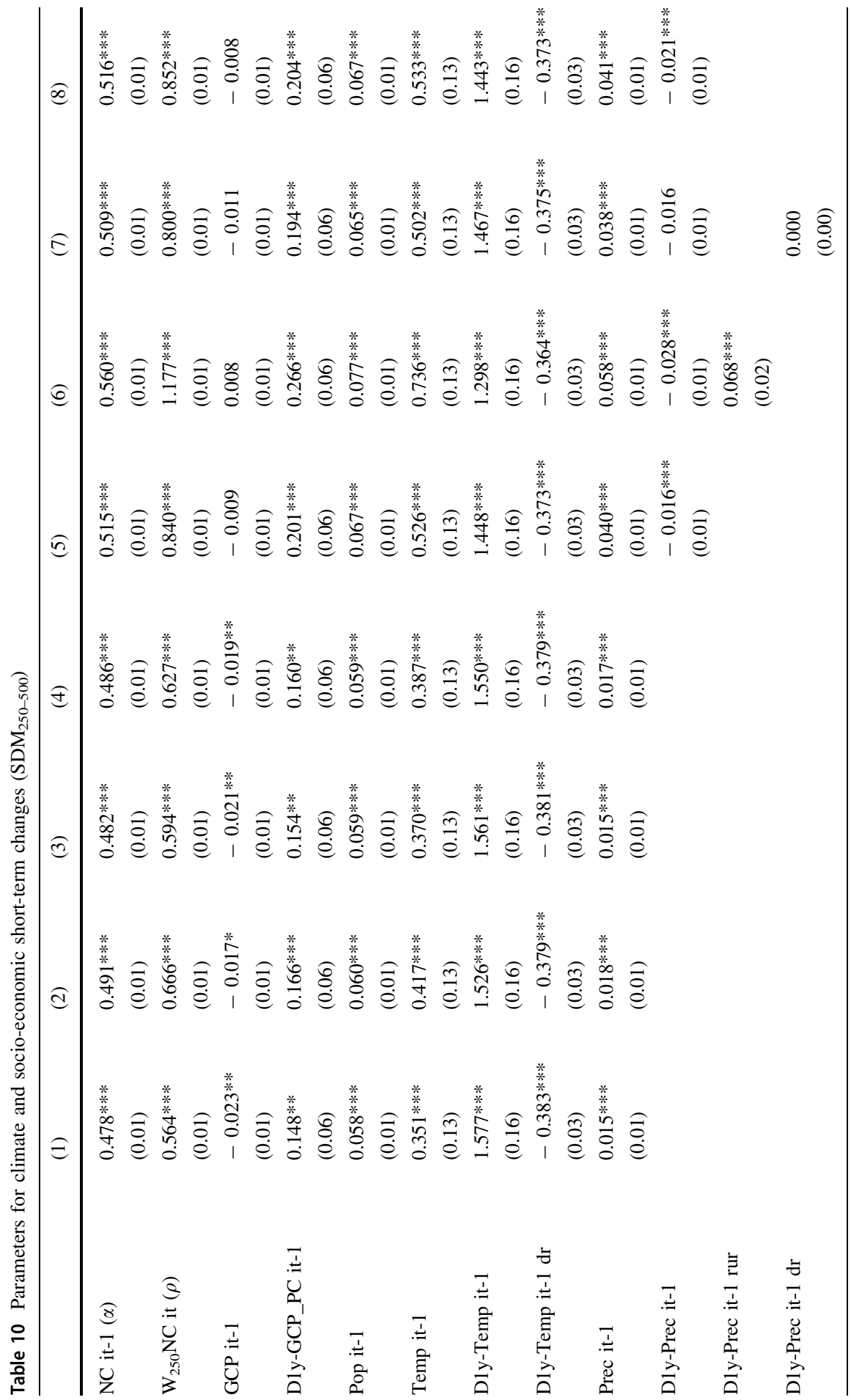




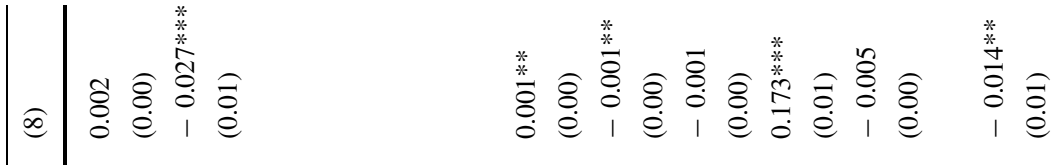

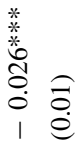

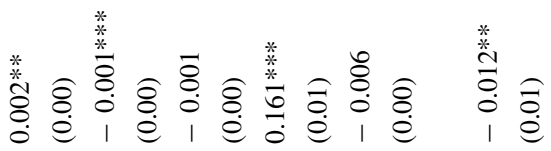

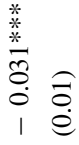

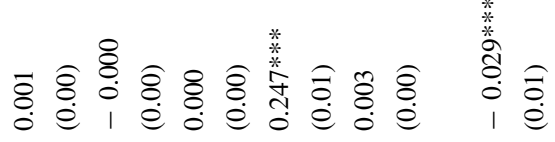

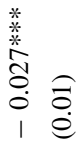

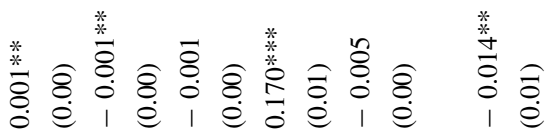

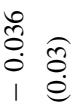

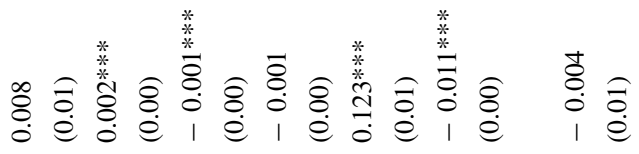

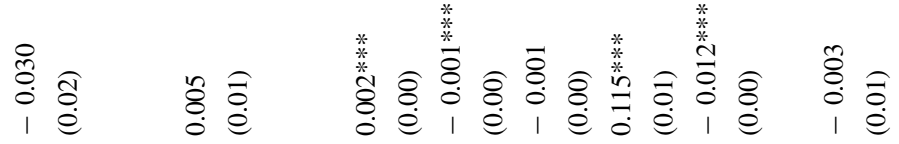

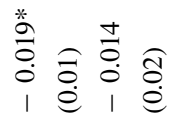

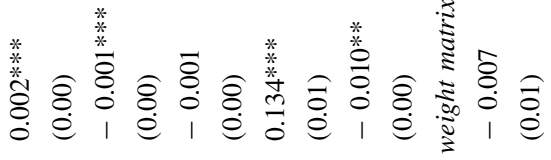

$$
\begin{aligned}
& \begin{array}{ll}
* \\
\stackrel{*}{*} \\
\stackrel{*}{0} & \widehat{0} \\
0 & \stackrel{0}{0}
\end{array}
\end{aligned}
$$

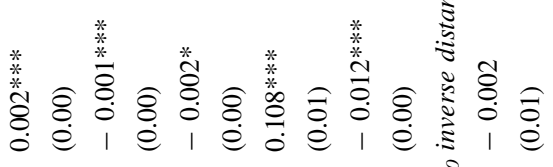

$$
\begin{aligned}
& \stackrel{3}{\frac{3}{2}} \\
& \text { ป }
\end{aligned}
$$

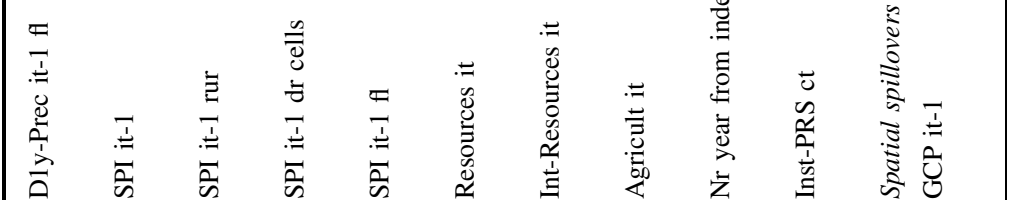




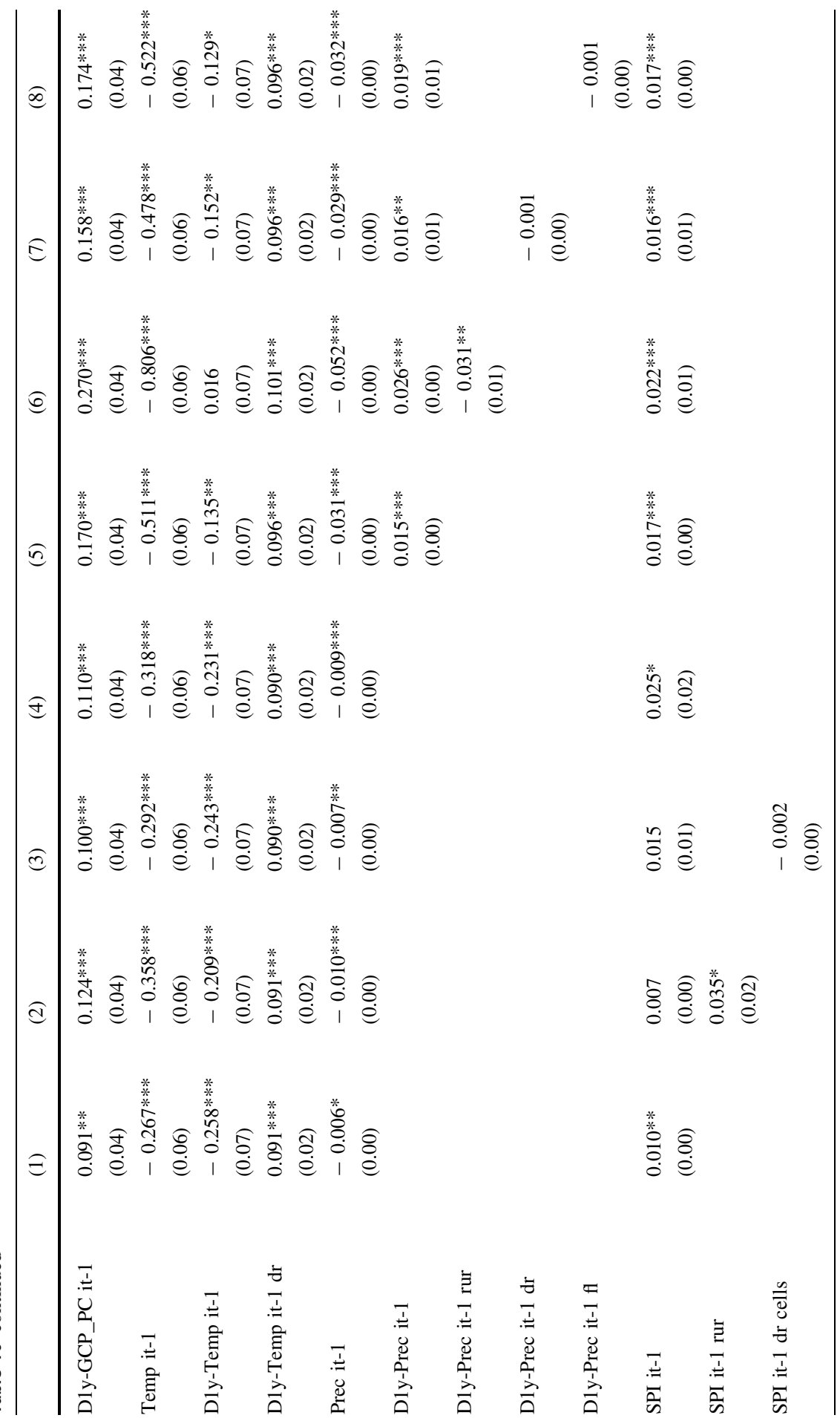




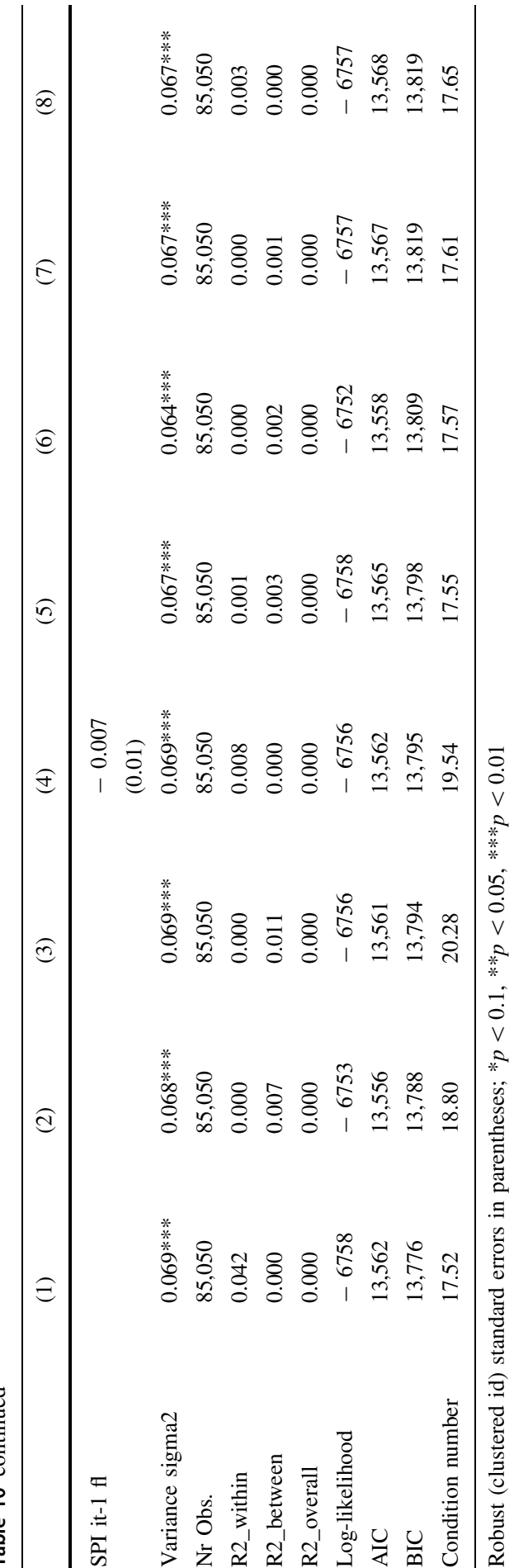




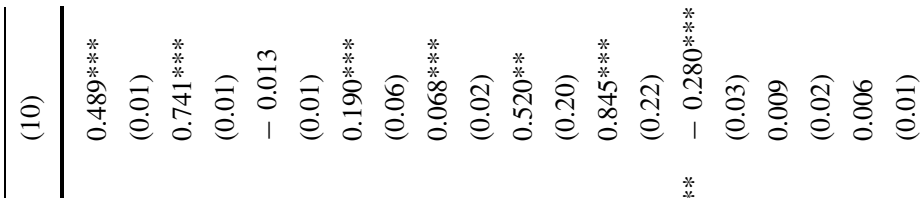

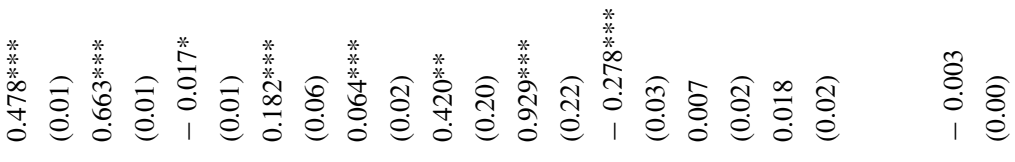

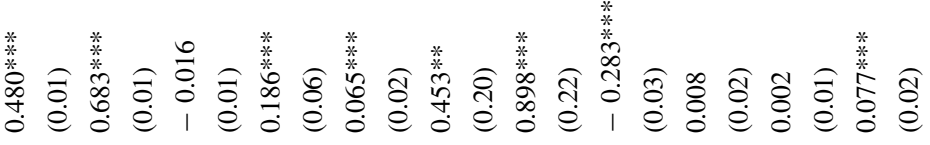

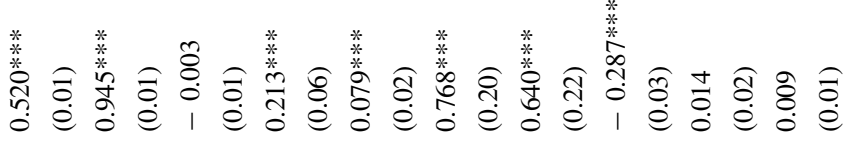

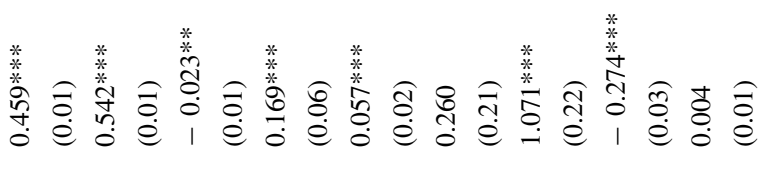

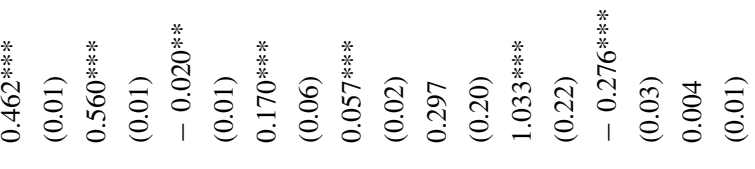

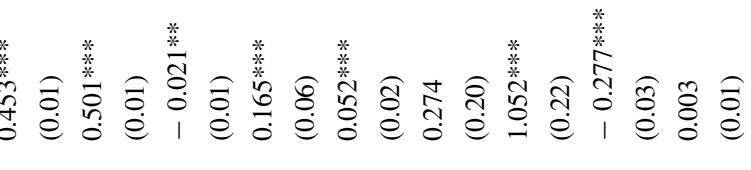

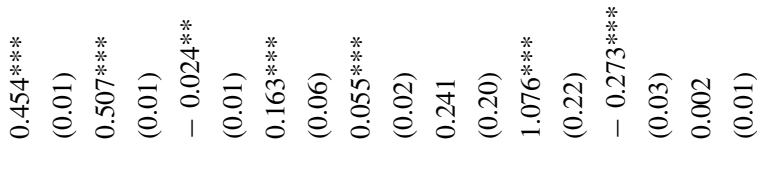

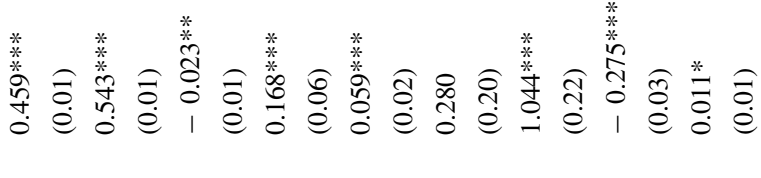

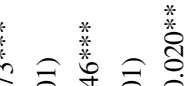

華

*

\section{*}




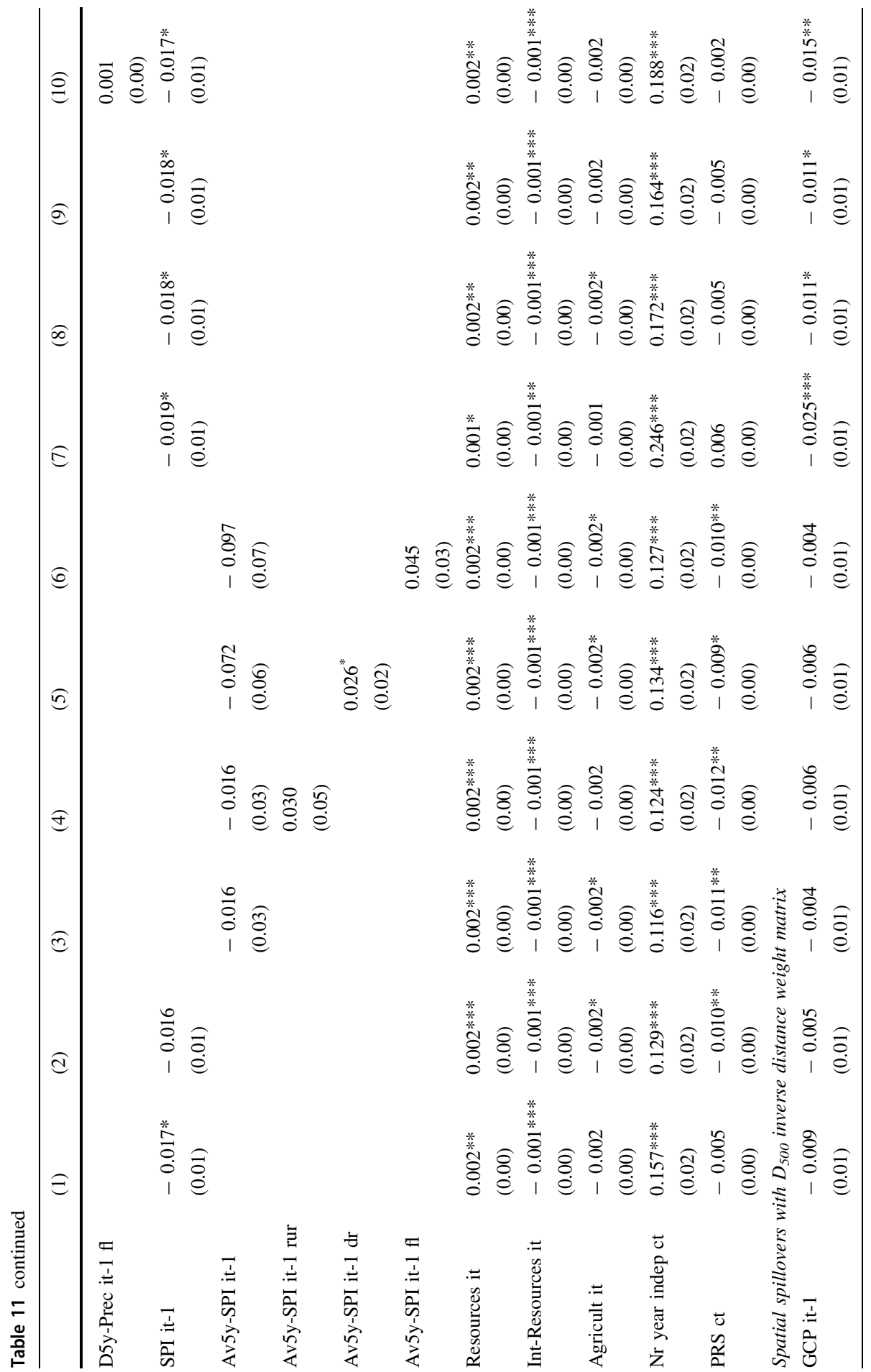




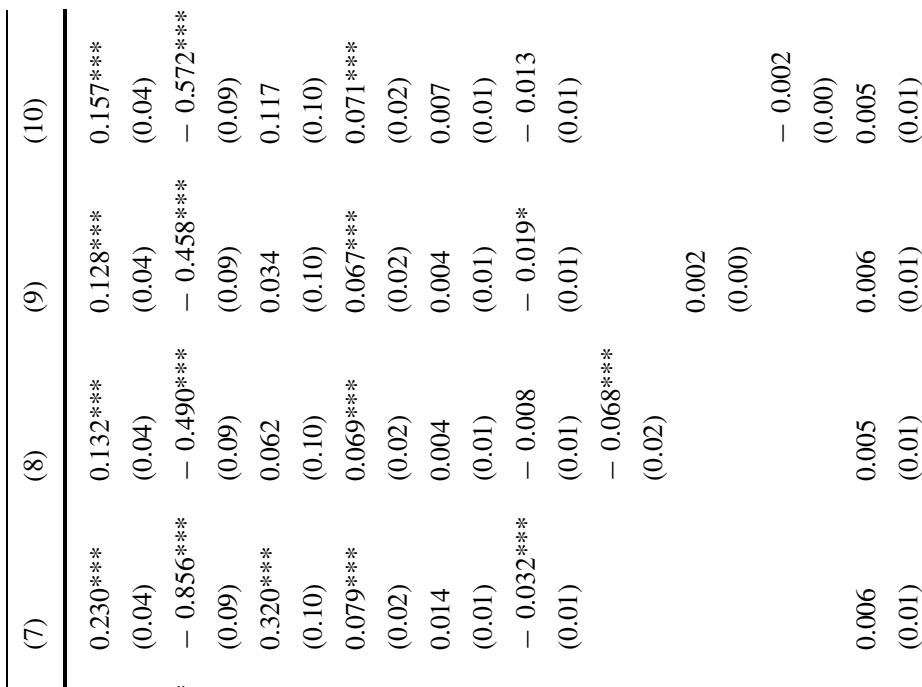

$\stackrel{*}{\stackrel{f}{0}} \stackrel{0}{0}$

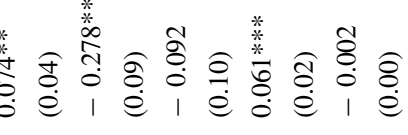

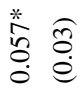

$*$
$*$
$\stackrel{*}{0}$
0
0
1

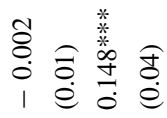

$\stackrel{m}{\overparen{a}}$

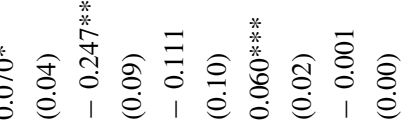

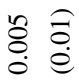

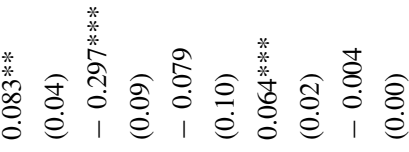

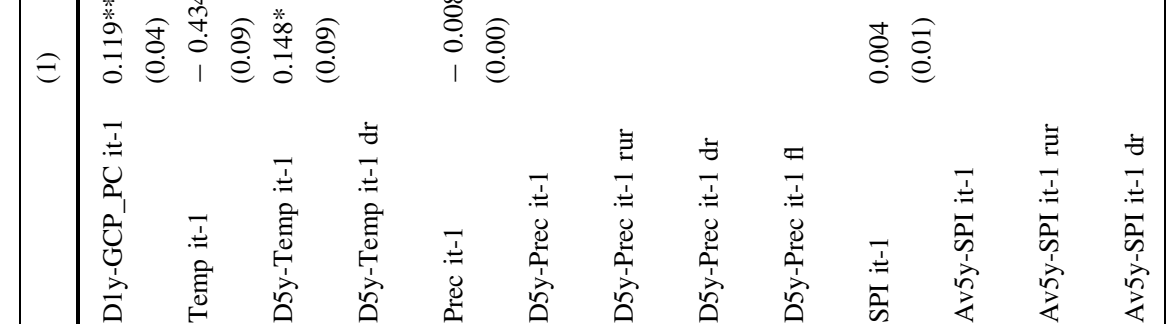




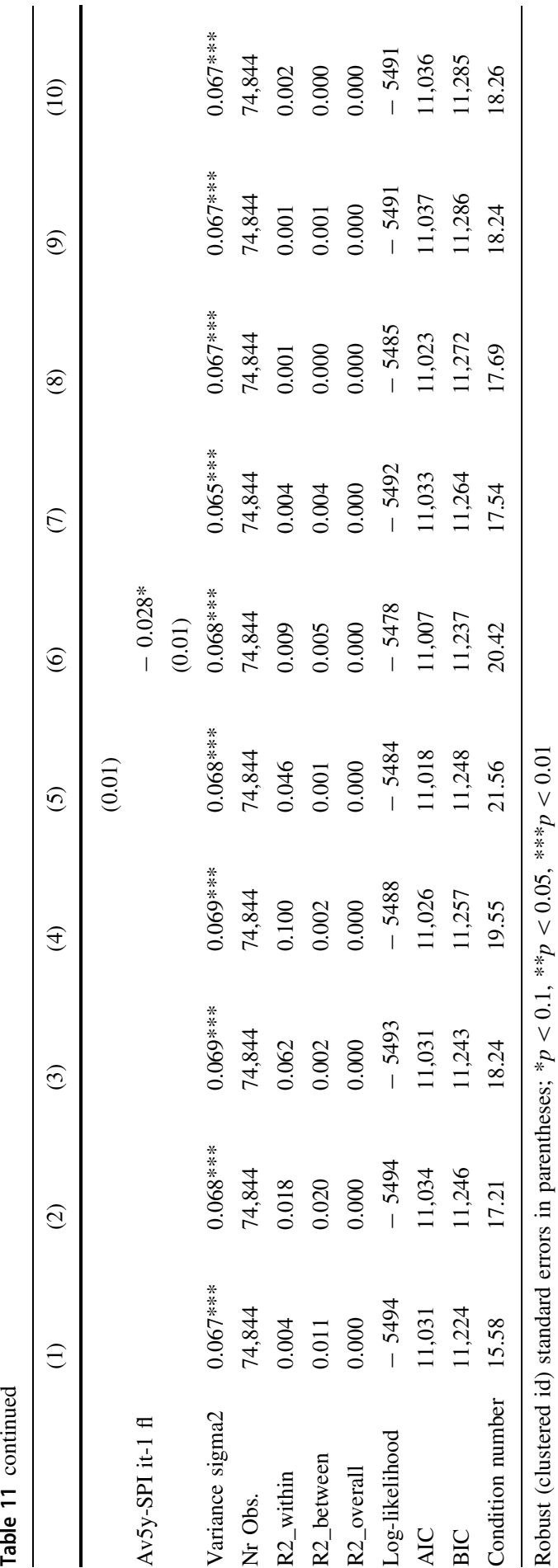




\section{References}

Adams C, Ide T, Barnett J, Detges A (2018) Sampling bias in climate-conflict research. Nat Clim Change $8(3): 200$

Adano WR, Dietz T, Witsenburg K, Zaal F (2012) Climate change, violent conflict and local institutions in Kenya's drylands. J Peace Res 49:65-80

Anselin L (1988) Spatial econometrics: methods and models. Kluwer, Dordrecht

Anselin L, Bera AK, Florax R, Yoon MJ (1996) Simple diagnostic tests for spatial dependence. Reg Sci Urban Econ 26:77-104

Arbia G, Patuelli R (2016) Spatial econometric interaction modelling. Springer, Heidelberg

Auffhammer M, Hsiang SM, Schlenker W, Sobel A (2013) Using weather data and climate model output in economic analyses of climate change. Review Environ Econ Policy 7:181-198

Barnett J, Adger WN (2007) Climate change, human security and violent conflict. Polit Geogr 26:639-655

Basedau M, Rustad SA, Must E (2018) Do expectations on oil discoveries affect civil unrest? Micro-level evidence from Mali. Cogent Soc Sci 4:1-19

Beger A (2012) Predicting the intensity and location of violence in war. The Florida State University

Belotti F, Hughes G, Mortari AP (2017) Spatial panel-data models using Stata. Stat J 17:139-180

Billor N, Hadi AS, Velleman PF (2000) BACON: blocked adaptive computationally efficient outlier nominators. Comput Stat Data Anal 34:279-298

Bodea C, Higashijima M, Singh RJ (2016) Oil and civil conflict: Can public spending have a mitigation effect? World Dev 78:1-12

Buhaug H (2015) Climate-conflict research: some reflections on the way forward. Wiley Interdiscip Reviews Clim Change 6:269-275

Burke M, Hsiang SM, Miguel E (2015) Climate and conflict. Annu Review Econ 7:577-617

Busby JW, Smith TG, Krishnan N (2014) Climate security vulnerability in Africa mapping 3.01. Polit Geogr 43:51-67

Collier P (2003) Breaking the conflict trap: civil war and development policy. World Bank Publications

Croicu M, Sundberg R (2017) UCDP GED Codebook version 17.1. Department of Peace and Conflict Research, Uppsala University, available online at: http:/ucdp.uu.se/downloads/ged/ged181.pdf. Accessed 08 Jan 2019

Dell M, Jones BF, Olken BA (2014) What do we learn from the weather? The new climate-economy literature. J Econ Lit 52(3):740-798

Devlin C, Hendrix CS (2014) Trends and triggers redux: climate change, rainfall, and interstate conflict. Polit Geogr 43:27-39

Eck K (2012) In data we trust? A comparison of UCDP GED and ACLED conflict events datasets. Cooper Conflict 47:124-141

Eckstein D, Künzel V, Schäfer L (2017) Global climate risk index 2018: Who suffers most from extreme weather events? Weather-Related Loss Events in 2016 and 1997 to 2016. Germanwatch Nord-Süd Initiative $\mathrm{eV}$

Elhorst JP (2001) Dynamic models in space and time. Geogr Anal 33:119-140

Elhorst JP (2009) Spatial panel data models. handbook of applied spatial analysis: software tools, methods and applications. In: Fischer MM, Getis A (eds) Handbook of applied spatial analysis: software tools, methods and applications. Springer, Berlin, pp 377-407

Elhorst JP (2012) Dynamic spatial panels: models, methods, and inferences. J Geogr Syst 14:5-28

Elhorst JP (2014) Spatial econometrics: from cross-sectional data to spatial panels. Springer, Heidelberg

Ember CR, Abate Adem T, Skoggard I, Jones EC (2012) Livestock raiding and rainfall variability in Northwestern Kenya. Civ Wars 14:159-181

Fjelde H, von Uexküll N (2012) Climate triggers: rainfall anomalies, vulnerability and communal conflict in Sub-Saharan Africa. Polit Geogr 31:444-453

Gates S, Hegre H, Nygård HM, Strand H (2012) Development consequences of armed conflict. World Dev 40:1713-1722

Glaser S (2017) A review of spatial econometric models for count data. Hohenheim Discussion Papers in Business, Economics and Social Sciences No. 19-2017

Gleditsch NP, Wallensteen P, Eriksson M, Sollenberg M, Strand H (2002) Armed conflict 1946-2001: a new dataset. J Peace Res 39:615-637 
Harari M, La Ferrara E (2018) Conflict, climate, and cells: a disaggregated analysis. Review Econ Stat 100:594-608

Högblad S (2019) UCDP GED Codebook version 19.1. Department of Peace and Conflict Research, Uppsala University

Hsiang SM, Meng KC, Cane MA (2011) Civil conflicts are associated with the global climate. Nature 476:438-441

Ide T (2017) Research methods for exploring the links between climate change and conflict. Wiley Interdiscip Reviews Clim Change 8(3):e456

Ide T, Scheffran J (2014) On climate, conflict and cumulation: suggestions for integrative cumulation of knowledge in the research on climate change and violent conflict. Glob Change Peace Secur 26:263-279

Ide T, Schilling J, Link JSA, Scheffran J, Ngaruiya G, Weinzierl T (2014) On exposure, vulnerability and violence: spatial distribution of risk factors for climate change and violent conflict across Kenya and Uganda. Polit Geogr 43:68-81

Jehn K, Rispens S, Jonsen K, Greer L (2013) Conflict contagion: a temporal perspective on the development of conflict within teams. Int J Conflict Manag 244:352-373

Kelejian HH, Prucha IR (2010) Specification and estimation of spatial autoregressive models with autoregressive and heteroskedastic disturbances. J Econom 157:53-67

Koubi V (2019) Climate change and conflict. Annu Rev Polit Sci 22:343-360

Koubi V, Bernauer T, Kalbhenn A, Spilker G (2012) Climate variability, economic growth, and civil conflict. J Peace Res 49(1):113-127

Kummu M, Taka M, Guillaume JH (2018) Gridded global datasets for gross domestic product and Human Development Index over 1990-2015. Sci Data 5:180004

Lambert DM, Brown JP, Florax RJ (2010) A two-step estimator for a spatial lag model of counts: theory, small sample performance and an application. Reg Sci Urban Econ 40:241-252

Lee LF, Yu J (2010) A spatial dynamic panel data model with both time and individual fixed effects. Econom Theory 26:564-597

LeSage JP, Dominguez M (2012) The importance of modeling spatial spillovers in public choice analysis. Public Choice 150(3-4):525-545

LeSage JP, Pace RK (2009) Introduction to spatial econometrics. CRC Press, Taylor Francis Group, Boca Raton

LeSage JP, Pace RK (2014) The biggest myth in spatial econometrics. Econometrics 2:217-249

Linke AM, Witmer FDW, O'Loughlin J, McCabe JT, Tir J (2018) The consequences of relocating in response to drought: human mobility and conflict in contemporary Kenya. Environ Res Lett 13:094014

Mach KJ, Kraan CM, Adger WN et al (2019) Climate as a risk factor for armed conflict. Nature 571:193-197

Maystadt JF, Ecker O (2014) Extreme weather and civil war: Does drought fuel conflict in somalia through livestock price shocks? Am J Agr Econ 96:1157-1182

Maystadt JF, Calderone M, You L (2015) Local warming and violent conflict in North and South Sudan. J Econ Geogr 15:649-671

Miguel E, Satyanath S, Sergenti E (2004) Economic shocks and civil conflict: an instrumental variables approach. J Polit Econ 112:725-753

Moore F, Diaz DB (2015) Temperature impacts on economic growth warrant stringent mitigation policy. Nat Clim Change 5:127-131

O'Loughlin J, Witmer FDW, Linke AM, Laing A, Gettelman A, Dudhia J (2012) Climate variability and conflict risk in East Africa, 1990-2009. Proc Natl Acad Sci USA 109(45):18344-18349

Ord K (1975) Estimation methods for models of spatial interaction. J Am Stat Assoc 70:120-126

Otto IM, Reckien D, Reyer CP, Marcus R, Le Masson V, Jones L, Serdeczny O (2017) Social vulnerability to climate change: a review of concepts and evidence. Reg Environ Change 17:1651-1662

Raleigh C, Kniveton D (2012) Come rain or shine: an analysis of conflict and climate variability in East Africa. J Peace Res 49:51-64

Salehyan I (2014) Climate change and conflict: making sense of disparate findings. Polit Geogr 43:1-5

Sarmidi T, Hook Law S, Jafari Y (2014) Resource curse: new evidence on the role of institutions. Int Econ J 28:191-206

Schleussner C-F, Dongesa JF, Donnera RV, Schellnhuber HJ (2016) Armed-conflict risks enhanced by climate-related disasters in ethnically fractionalized countries. PNAS 113:9216-9221 
Selby J (2014) Positivist climate conflict research: a critique. Geopolitics 19:829-856

Sundberg R, Melander E (2013) Introducing the UCDP georeferenced event dataset. J Peace Res 50:523-532

Vogt M, Bormann N-C, Ruegger S, Cederman L-E, Hunziker P, Girardin L (2015) Integrating data on ethnicity, geography, and conflict: the ethnic power relations data set family. J Conflict Resolut 59:1327-1342

von Uexküll N, Croicu M, Fjelde H, Buhaug H (2016) Civil conflict sensitivity to growing-season drought. PNAS 113:12391-12396

Weidmann NB, Rød JK, Cederman LE (2010) Representing ethnic groups in space: a new dataset. J Peace Res 47(4):491-499

Weintrit A, Kopacz P (2011) A Novel Approach to Loxodrome (Rhumb-Line), Orthodrome (Great Circle) and Geodesic Line in ECDIS and Navigation in General." Methods and Algorithms in Navigation, Marine Navigation and Safety of Sea Transportation. Leiden: A Balkema Book, CRC Press, Taylor and Francis: 123-132

WMO (2018) WMO Statement on the state of the global climate in 2017. Working Document No 1212 , Geneva, Switzerland

Yu J, de Jong R, Lee LF (2008) Quasi-maximum likelihood estimators for spatial dynamic panel data with fixed effects when both $\mathrm{N}$ and $\mathrm{T}$ are large. J Econom 146:118-134

Yu J, de Jong R, Lee LF (2012) Estimation for spatial dynamic panel data with fixed effects: the case of spatial cointegration. J Econom 167:16-37

Publisher's Note Springer Nature remains neutral with regard to jurisdictional claims in published maps and institutional affiliations.

\title{
Affiliations
}

\section{Federica Cappelli ${ }^{1}$ - Caterina Conigliani ${ }^{1} \cdot$ Valeria Costantini $^{1,2}$ (D) Keti Lelo ${ }^{1} \cdot$ Anil Markandya $^{3} \cdot$ Elena Paglialunga $^{4} \cdot$ Giorgia Sforna $^{5}$}

\author{
\aleria Costantini \\ valeria.costantini@uniroma3.it \\ Federica Cappelli \\ federica.cappelli@uniroma3.it \\ Caterina Conigliani \\ caterina.conigliani@uniroma3.it \\ Keti Lelo \\ keti.lelo@uniroma3.it \\ Anil Markandya \\ anil.markandya@bc3research.org \\ Elena Paglialunga \\ elena.paglialunga@uniurb.it \\ Giorgia Sforna \\ giorgia.sforna@enea.it \\ 1 University of Roma Tre, Rome, Italy \\ 2 GREDEG-UNS, Nice, France
}


3 Basque Centre for Climate Change (BC3), Leioa, Spain

4 University of Urbino, Urbino, Italy

5 ENEA, Rome, Italy 